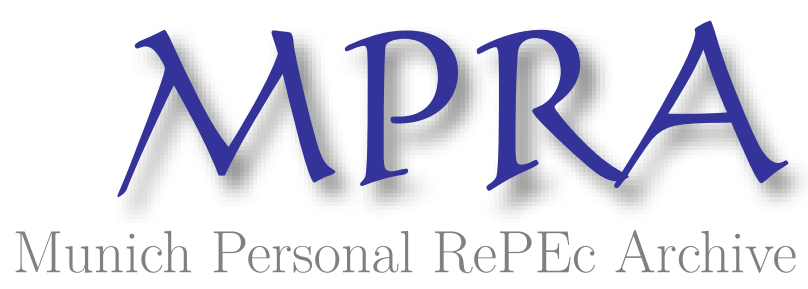

\title{
Technology Shocks, Statistical Models, and The Great Moderation
}

Fuentes-Albero, Cristina

University of Pennsylvania

1 June 2007

Online at https://mpra.ub.uni-muenchen.de/3589/

MPRA Paper No. 3589, posted 16 Jun 2007 UTC 


\title{
Technology Shocks, Statistical Models, and The Great Moderation
}

\author{
Cristina Fuentes-Albero \\ University of Pennsylvania*
}

June 1, 2007

\begin{abstract}
In this paper we compare the cyclical features implied by an RBC model with two technology shocks under several statistical specifications for the stochastic processes governing technological change. We conclude that while a trend-stationary model accounts better for the observed volatilities, a difference-stationary model does a relatively better job of accounting for the correlation of the variables of interest with output. We also explore some counterfactuals to assess the ability of our model to replicate the volatility slowdown of the mid 1980s. First, we conclude that the stochastic growth model outperforms the deterministic growth model in accounting for the Great Moderation. Finally, we obtain that even though the neutral technology shock is the main driving force in the volatility slowdown, allowing for a larger financial flexibility in the form of a smaller volatility for the investment-specific innovation improves the ability of our model to account for the magnitude of the Great Moderation.
\end{abstract}

Keywords: Business Cycle, Aggregate fluctuations, Technology Shocks, Unit Roots JEL Classification: E32, O30, 041, C32

*fuentesa@sas.upenn.edu. I would like to thank Dionissi Aliprantis, Jonas Fisher, Jeremy Greenwood, Maxym Kryshko, Leonardo Melosi, Víctor Ríos-Rull, Raül Santaeulàlia, and Frank Schorfheide. 


\section{Introduction}

Technology driven business cycles have been in the core of the Real Business Cycle literature from its origins. For example Prescott (1986) claims that technology shocks account for more than a half of the US business cycle fluctuations over the postwar period. In Cooley and Prescott (1995), technology shocks account for more than $75 \%$ of the volatility of output. Such an empirical success has been questioned by Galí (1999) and Galí and Rabanal (2004) among others. They claim that business cycle features are due mainly to non-technology factors. However, Greenwood, Hercowitz, and Krusell (1997) started a new wave of attention on technology-driven business cycles by allowing for not only a neutral technology shock, but also an investment-specific one.

In this paper we want to address the slowdown in volatility of macroeconomic variables in the US economy ${ }^{1}$ using a simple model inspired by Greenwood, Hercowitz, and Krusell (2000). We want to determine whether the slowdown in the volatility of the two shocks under analysis suffices to explain a significant part of the so called Great Moderation. Arias, Hansen, and Ohanian (2007) consider a basic RBC model à la Hansen with only one technology shock. They conclude that such a model can account for a decline of about $50 \%$ in cyclical volatility. They also analyze a model based on Burnside and Eichenbaum (1996) with endogenous movements in TFP due to labor hoarding and capital utilization. They explore the explanatory power of different shocks and conclude that the most promising candidate for understanding the slowdown in volatility is a productivity-like shock.

We are interested in exploring the performance of our simple RBC model under three specifications for the technology processes. We will consider a general specification allowing for persistence but without imposing unit roots. Therefore, such a model will be trend stationary. Then, we will analyze two versions of a difference-stationary model. We want to determine which specification accounts better for the US business cycle features in the flavor of the analysis by Hansen (1997). He explores the specifications presented here in an economy with only one technology shock. He concludes that when technological progress is difference-stationary, the RBC model does a poor job accounting for features of observed business cycles.

We think it is challenging to analyze the explanatory power of those statistical models when the Great Moderation is at hand. In fact, we have found that while the deterministic

\footnotetext{
${ }^{1}$ See Appendix F
} 
growth model accounts better for observed volatilities, the stochastic growth models are preferable if we want to match correlations or address the slowdown in aggregate volatility observed in the mid 1980s.

Since Kim and Nelson (1999) and McConnell and Pérez-Quirós (2000) dated the starting of the Great Moderation ${ }^{2}$, there has been a growing literature on explaining what is behind such a phenomenon. Kahn, McConnell, and Pérez-Quirós (2002) claim that the change in inventory behavior due to improvement in information technology can explain the output volatility slowdown. Stock and Watson (2002), Kim, Morley, and Piger (2004), Ahmed, Levin, and Wilson (2004), Leduc and Sill (2006), and Arias, Hansen, and Ohanian (2007) use different approaches to conclude that the Great Moderation can be explained by 'good luck' in the form of smaller shocks. Dynan, Elmendorf, and Sichel (2005), Campbell and Hercowitz (2005), Dynan, Elmendorf, and Sichel (2006), Guerron (2006), Jermann and Quadrini (2006), and Justiniano and Primiceri (2006) claim that financial innovations are one of the possible contributing sources to the macro stability observed since mid 1980s. Many of them focus on financial innovations affecting households. Jermann and Quadrini (2006), however, focus on innovations that allow for greater financial flexibility of firms. The paper by Justiniano and Primiceri (2006) is remarkable because they propose the estimation of a DSGE model with time-varying volatilities. They, as Blanchard and Simon (2001), deny the existence of a structural break in the first quarter of 1984. However, they consider the volatility slowdown has been a long term phenomenon initiated in the 1950s and interrupted during 1970s and early 1980s.

Our results suggest that 'good luck' in the form of smaller innovations to the technology processes can account for the bulk of the volatility slowdown in our model. Moreover, we find that while the neutral technology shock plays the main role in explaining the reduction in macro volatility, its performance improves when the investment-technology shock is also at hand. Therefore, in our model economy, the Great Moderation is due not only to smaller shocks but also to lessened financial frictions. Note that we are considering, as Chari, Kehoe, and McGrattan (2004) suggest, that investment-specific technology shocks are a proxy for investment financial frictions.

The paper proceeds as follows. In section 2 we set up our baseline model. In section 3

\footnotetext{
${ }^{2}$ Stock and Watson (2002) came up with such an expression to refer to the slowdown in the volatility of macro variables in the US observed in the mid 1980s
} 
we proceed with our calibration exercises. We will study the three statistical models under analysis. Section 4 presents several counterfactuals in order to analyze the Great Moderation in the framework defined by our model economy. Section 5 concludes.

\section{The model}

The model is a simplified version of the one proposed by Greenwood, Hercowitz, and Krusell (2000). In particular, we will abstract from different capital goods and degrees of capital utilization. We will preserve, however, the existence of both a neutral and an investmentspecific technology shocks.

We will consider three statistical versions of the baseline model in order to assess which one accounts better for the US business cycle features. First, we will analyze a deterministic growth version of the model where the stochastic processes are trend stationary. Second, we will consider a stochastic growth model where the technology processes follow a unit root with drift. Finally, we will allow for some persistence to the innovation of the investment specific technology in a stochastic growth model. Therefore, in the first case we will study an economy where all shocks are temporary. In the second model, all shocks are permanent. In the last model, we will consider both permanent and transitory shocks. In particular, any neutral shock will be permanent, while any transitory shock will have both permanent and transitory effects.

Hansen (1997) performed a similar analysis to the one we propose here but considering a model with only a neutral technology shock. He concluded that the trend-stationary (but highly persistent) model does a better job accounting for the business cycle features than the difference-stationary one.

Since Nelson and Plosser (1982) there has been a large empirical literature about stochastic trends in macro variables. Unit roots and stationary processes differ in their implications at infinite time horizons, but for any given finite sample, there is a representative from either class of models that can account for all the observed features of the data ${ }^{3}$. In addition, the lack of power of univariate classical tests for unit roots is well known. Therefore, we have decided to choose among the three specifications described above using the following criterion: the most preferred statistical model will be the one able to account for a larger

\footnotetext{
${ }^{3}$ For a more detailed discussion on nonstationary time series see Hamilton (1994)
} 
proportion of the US business cycle properties. Note that we will be performing this test not only over the whole sample, but also over the two subsamples of interest.

In this economy there is a continuum of households that maximize their lifetime utility given by

$$
E_{0}\left[\sum_{t=0}^{\infty} \beta^{t} U\left(C_{t}, H_{t}\right)\right]
$$

with

$$
U\left(C_{t}, H_{t}\right)=\ln C_{t}-B \frac{H_{t}^{1+1 / \nu}}{1+1 / \nu}
$$

where $\nu$ stands for the short-run (Frisch) labor supply elasticity.

We have chosen such a specification because we are not interested in exploring the stationarity of hours issue ${ }^{4}$. Therefore, we will use a series for hours that is stationary in levels. It is well known that the log utility in consumption implies a constant long-run labor supply in response to a permanent change in technology. Hence, we do not have to worry about trending hours implied by our model even under the difference-stationary specification.

The representative household maximizes (1) subject to the following budget constraint

$$
C_{t}+\frac{K_{t+1}}{V_{t}}=W_{t} H_{t}+\left(1-\delta+R_{t}\right) \frac{K_{t}}{V_{t}}
$$

where $V_{t}$ stands for the current level of the investment-specific technology ${ }^{5}$. In particular, $V_{t}=\frac{1}{P_{t}^{k}}$ where $P_{t}^{k}$ is the (relative) price of investment. Therefore, the budget constraint is expressed in consumption units.

Optimal behavior requires

$$
\begin{aligned}
\frac{1}{C_{t} V_{t}} & =\beta E_{t}\left[\frac{1}{C_{t+1} V_{t+1}}\left(1-\delta+R_{t+1}\right)\right] \\
H_{t} & =\left(\frac{1}{B} \frac{W_{t}}{C_{t}}\right)^{\nu}
\end{aligned}
$$

\footnotetext{
${ }^{4}$ See Chang, Doh, and Schorfheide (2007) for an interesting treatment of such an issue and Christiano, Eichenbaum, and Vigfusson (2003) for an analysis of the implications of different labor input measures in a SVAR framework.

${ }^{5}$ Note that a higher $V$ implies a fall in the cost of producing a new unit of capital in terms of output. It could also be interpreted as an improvement in the quality of new capital produced with a given amount of resources.
} 
There is also a continuum of firms that rent capital and labor services from households. The representative firm solves the following problem $^{6}$ :

$$
\begin{aligned}
\max & \Pi_{t}=Y_{t}-W_{t} H_{t}-R_{t} \frac{K_{t}}{V_{t}} \\
\text { s.t. } & Y_{t}=A_{t} K_{t}^{\alpha} H_{t}^{1-\alpha}
\end{aligned}
$$

where $A$ is the neutral technology stochastic process.

Optimality requires:

$$
\begin{aligned}
W_{t} & =(1-\alpha) \frac{Y_{t}}{H_{t}} \\
R_{t} & =\alpha V_{t} \frac{Y_{t}}{K_{t}}
\end{aligned}
$$

The capital accumulation equation is given by

$$
(1+\eta) K_{t+1}=(1-\delta) K_{t}+X_{t}
$$

where $\eta$ is the population growth $\operatorname{rate}^{7}$ and $X_{t}=V_{t} I_{t}$. Note that the investment equation is in efficiency units.

Finally, let us consider the three statistical specifications for the stochastic processes. In the deterministic growth model the technology processes are modeled as follows:

$$
\begin{gathered}
A_{t}=A_{0} e^{\gamma_{a} t+\varepsilon_{a t}} \\
V_{t}=V_{0} e^{\gamma_{v} t+\varepsilon_{v t}}
\end{gathered}
$$

The assumptions on the error structure will be explicit in the next section.

In the baseline stochastic growth model, the processes are given by

$$
\begin{aligned}
A_{t} & =A_{t-1} e^{\gamma_{a}+\varepsilon_{a t}} \\
V_{t} & =V_{t-1} e^{\gamma_{v}+\varepsilon_{v t}}
\end{aligned}
$$

Finally, in the last statistical model we will allow for persistence in $\varepsilon_{v}$.

\footnotetext{
${ }^{6}$ When we proceed with calibration we will introduce an additional parameter $\mu$ in the production function so that output at steady state is equal to 1

${ }^{7}$ As usual we are considering per capita terms in our model
} 
Under all the specifications our model economy exhibits long-run growth. Therefore, we will transform our economy so that we can work with a detrended version of the original one. Under the first statistical model we know that the following variables are stationary ${ }^{8}$

$$
\frac{Y_{t}}{q^{t}}, \frac{C_{t}}{q^{t}}, \frac{I_{t}}{q^{t}}, \frac{W_{t}}{q^{t}}, \frac{K_{t}}{(q v)^{t}}, \quad H_{t}, \quad R_{t}
$$

where

$$
q=e^{\frac{1}{1-\alpha} \gamma_{a}+\frac{\alpha}{1-\alpha} \gamma_{v}}
$$

and

$$
v=e^{\gamma_{v}}
$$

Let us denote a stationary variable $Z$ by $\tilde{Z}$. Therefore, the stationary equilibrium conditions for this statistical version of the model are given by:

$$
\begin{aligned}
\tilde{Y}_{t} & =\tilde{C}_{t}+\tilde{I}_{t} \\
\tilde{Y}_{t} & =A_{0} e^{\varepsilon_{a t}} \tilde{K}_{t}^{\alpha} H_{t}^{1-\alpha} \\
(1+\eta) q v \tilde{K}_{t+1} & =(1-\delta) \tilde{K}_{t}+V_{0} e^{\varepsilon_{v t}} \tilde{I}_{t} \\
1 & =\beta E_{t}\left[\left(\frac{e^{\varepsilon_{v t}-\varepsilon_{v t+1}}}{q v}\right)\left(\frac{\tilde{C}_{t}}{\tilde{C}_{t+1}}\right)\left(1-\delta+R_{t+1}\right)\right] \\
H_{t} & =\left(\frac{1}{B} \frac{\tilde{W}_{t}}{\tilde{C}_{t}}\right)^{\nu} \\
R_{t} & =\alpha V_{0} e^{\varepsilon_{v t}} \frac{\tilde{Y}_{t}}{\tilde{K}_{t}} \\
\tilde{W}_{t} & =(1-\alpha) \frac{\tilde{Y}_{t}}{H_{t}}
\end{aligned}
$$

Given the detrended version of our economy we can solve for the steady state. Let us denote the steady state value of a variable $Z$ by $Z^{*}$.

$$
\begin{aligned}
Y^{*} & =C^{*}+I^{*} \\
Y^{*} & =A_{0} K^{* \alpha} H^{*(1-\alpha)} \\
(1+\eta) q v K^{*} & =(1-\delta) K^{*}+V_{0} I^{*} \\
1 & =\beta\left(\frac{1}{q v}\right)\left(1-\delta+R^{*}\right)
\end{aligned}
$$

\footnotetext{
${ }^{8}$ See the appendix for a detailed explanation on obtaining the growth rates for this economy
} 


$$
\begin{aligned}
H^{*} & =\left(\frac{1}{B} \frac{W^{*}}{C^{*}}\right)^{\nu} \\
R^{*} & =\alpha V_{0} \frac{Y^{*}}{K^{*}} \\
W^{*} & =(1-\alpha) \frac{Y^{*}}{H^{*}}
\end{aligned}
$$

Let us consider now the two difference-stationary models. Beveridge and Nelson (1981) showed in a model with only one shock that any of the trending variables of these kinds of models can be decomposed into a permanent component that is a random walk with drift (a stochastic trend) and a stationary stochastic process. In our case we have to take into account that the two stochastic processes have a unit root ${ }^{9}$. Hence, given such a statistical model, we have that the following variables are stationary

$$
\frac{C_{t}}{Q_{t}}, \quad \frac{I_{t}}{Q_{t}}, \quad \frac{Y_{t}}{Q_{t}}, \quad H_{t}, \quad R_{t}, \quad \frac{K_{t+1}}{Q_{t} V_{t}}, \quad \frac{W_{t}}{Q_{t}}
$$

where $Q_{t}=A_{t}^{\frac{1}{1-\alpha}} V_{t}^{\frac{\alpha}{1-\alpha}}$.

The stationary equilibrium conditions are:

$$
\begin{aligned}
\tilde{Y}_{t} & =\tilde{C}_{t}+\tilde{I}_{t} \\
\tilde{Y}_{t} & =\left(\frac{1}{q_{t} v_{t}}\right)^{\alpha} \tilde{K}_{t}^{\alpha} H_{t}^{1-\alpha} \\
(1+\eta) \tilde{K}_{t+1} & =(1-\delta)\left(\frac{1}{q_{t} v_{t}}\right) \tilde{K}_{t}+\tilde{I}_{t} \\
1 & =\beta E_{t}\left[\left(\frac{1}{q_{t+1} v_{t+1}}\right)\left(\frac{\tilde{C}_{t}}{\tilde{C}_{t+1}}\right)\left(1-\delta+R_{t+1}\right)\right] \\
H_{t} & =\left(\frac{1}{B} \frac{\tilde{W}_{t}}{\tilde{C}_{t}}\right)^{\nu} \tilde{\tilde{Y}}_{t} \\
R_{t} & =\alpha\left(q_{t} v_{t}\right) \frac{\tilde{K}_{t}}{\tilde{Y}_{t}} \\
\tilde{W}_{t} & =(1-\alpha) \frac{\tilde{H}_{t}}{H_{t}}
\end{aligned}
$$

where

$$
q_{t}=\frac{Q_{t}}{Q_{t-1}}=e^{\frac{1}{1-\alpha}\left(\gamma_{a}+\varepsilon_{a t}\right)+\frac{\alpha}{1-\alpha}\left(\gamma_{v}+\varepsilon_{v t}\right)}
$$

\footnotetext{
${ }^{9}$ For detrending issues there is no difference between having just a random walk with drift or a random walk with drift plus a moving average component.
} 


$$
v_{t}=\frac{V_{t}}{V_{t-1}}=e^{\gamma_{v}+\varepsilon_{v t}}
$$

Given that the stationary version of the difference-stationary model satisfies the usual assumptions, we can solve for the steady-state of this transformed economy. Then,

$$
\begin{aligned}
Y^{*} & =C^{*}+I^{*} \\
Y^{*} & =\left(\frac{1}{q^{*} v^{*}}\right)\left(K^{*}\right)^{\alpha}\left(H^{*}\right)^{1-\alpha} \\
(1+\eta) K^{*} & =(1-\delta)\left(\frac{1}{q^{*} v^{*}}\right) K^{*}+I^{*} \\
1 & =\beta\left(\frac{1}{q^{*} v^{*}}\right)\left(1-\delta+R^{*}\right) \\
H^{*} & =\left(\frac{1}{B} \frac{W^{*}}{C^{*}}\right)^{\nu} \\
R^{*} & =\alpha q^{*} v^{*} \frac{Y^{*}}{K^{*}} \\
W^{*} & =(1-\alpha) \frac{Y^{*}}{H^{*}}
\end{aligned}
$$

where

$$
\begin{aligned}
q^{*} & =e^{\frac{1}{1-\alpha} \gamma_{a}+\frac{\alpha}{1-\alpha} \gamma_{v}} \\
v^{*} & =e^{\gamma_{v}}
\end{aligned}
$$

\section{Calibration}

\subsection{Deterministic Growth Model}

We will consider the following statistical specification:

$$
\begin{aligned}
\ln A_{t} & =\ln A_{0}+\gamma_{a} t+\varepsilon_{a t} \\
\ln V_{t} & =\ln V_{0}+\gamma_{v} t+\varepsilon_{v t}
\end{aligned}
$$

While the investment-specific process is approximated by the inverse of the (relative) price of investment, the neutral technology process is associated with the Solow residual of this economy. Note that we are assuming a linear time trend for both stochastic processes which will imply a deterministic trend in many of the variables in our model. Alternatively, 
following Gomme and Rupert (2007) we could have hp-filtered or band-pass filtered $\left\{\ln A_{t}\right\}$ and $\left\{\ln V_{t}\right\}$ and assume an autoregressive process on the cyclical component of both series.

In the literature we find different ways of computing the quarterly Solow residual. Cooley and Prescott (1995) claim that as the BEA produces only annual estimates for the capital stock, any quarterly series will introduce additional noise in the measure of the Solow residual. Therefore, they propose a 'conservative' approach by omitting capital when computing the neutral technology process. This approach has been widely used in the literature, for a recent example see Arias, Hansen, and Ohanian (2007). Gomme and Rupert (2007) establish that another justification for omitting capital could be measurement errors. However, mismeasurement affects the level of the capital stock but not its time series properties. Thus, other approaches construct quarterly capital series by iterating on the law of motion for capital. Note that as Greenwood, Hercowitz, and Krusell (1997) point out, we have to be careful when constructing our capital stock series since it must be in efficiency units. Figure 1 reports the two alternative measures of the Solow residual ${ }^{10}$. We will proceed with the one that takes into account quarterly capital stock series conveniently corrected by quality improvement. We will be using the database constructed by Víctor Ríos-Rull, Raül Santaeulàlia, and Frank Schorfheide ${ }^{11}$.

The econometric strategy is as follows:

1. Regress each technology process on a constant and a linear time trend

$$
\begin{aligned}
\ln A_{t} & =\varphi_{a}+\gamma_{a} t+\varepsilon_{a t} \\
\ln V_{t} & =\varphi_{v}+\gamma_{v} t+\varepsilon_{v t}
\end{aligned}
$$

2. Generate the corresponding residual series $\left\{\hat{\varepsilon}_{a t}\right\}$ and $\left\{\hat{\varepsilon}_{v t}\right\}$.

3. Estimate univariate autoregressive processes for those shocks

$$
\begin{aligned}
\varepsilon_{a t} & =\rho_{a} \varepsilon_{a t-1}+\xi_{a t} \\
\varepsilon_{v t} & =\rho_{v 1} \varepsilon_{v t-1}+\rho_{v 2} \varepsilon_{v t-2}+\xi_{v t}
\end{aligned}
$$

where $\xi_{a} \sim \mathcal{N}\left(0, \sigma_{\xi_{a}}^{2}\right)$ and $\xi_{v} \sim \mathcal{N}\left(0, \sigma_{\xi_{v}}^{2}\right)$.

\footnotetext{
${ }^{10}$ To make easier the comparison we have normalize the first observation for both series equal to 1

${ }^{11}$ They kindly provided their database. Jonas Fisher also made available his investment price series.
} 
The estimated parameters are reported in table 1. We observe that in the post-1984 period there has been a $48 \%$ reduction in the volatility of the innovation to the neutral technology and a $40 \%$ reduction in the volatility of the innovation to the investment-specific technology. We will analyze in section 5 if such a reduction in innovations' volatilities suffices to explain the slowdown in the volatility of the macro variables of interest.

In our model the vector of parameters is given by

$$
\left(\alpha, \gamma_{a}, \gamma_{v}, \beta, \delta, B, \nu, \eta, \mu, \varphi_{a}, \varphi_{v}, \rho_{a}, \rho_{v 1}, \rho_{v 2}, \sigma_{\xi_{a}}, \sigma_{\xi_{v}}\right)
$$

where $\mu$ is a scaling parameter. We can estimate $\left(\alpha, \gamma_{a}, \gamma_{v}, \eta, \varphi_{a}, \varphi_{v}, \rho_{a}, \rho_{v 1}, \rho_{v 2}, \sigma_{\xi_{a}}, \sigma_{\xi_{v}}\right)$ from the data. In order to calibrate the remaining parameters we will consider the following targets:

Table 1: Calibration Targets

\begin{tabular}{|lc|c|c|}
\hline \hline & $1948: 1-2006: 4$ & $1948: 1-1983: 4$ & $1984: 1-2006: 4$ \\
\hline \hline$H^{*}$ & 0.31 & 0.31 & 0.31 \\
\hline$Y^{*}$ & 1 & 1 & 1 \\
\hline$\left(\frac{K / V}{Y}\right)^{*}$ & 10.288 & 10.502 & 9.953 \\
\hline$\left(\frac{X}{K}\right)^{*}$ & 0.0277 & 0.0276 & 0.0279 \\
\hline$\left(\frac{I}{Y}\right)^{*}$ & 0.28 & 0.29 & 0.28 \\
\hline \hline
\end{tabular}


Given our specification we cannot calibrate both $\nu$ and $B$. In fact, our calibrated $B$ will be conditional on the choice for the Frisch elasticity parameter. In the literature we find values for such a parameter ranging from 0.5 to 2 . We will simulate our model for $\nu=\{0.5,1,1.5,2\}$. The calibrated parameters are reported in table 2.

Table 2: Deterministic Trend: Calibrated Parameters

\begin{tabular}{|lc|c|c|}
\hline \hline & $1948: 1-2006: 4$ & $1948: 1-1983: 4$ & $1984: 1-2006: 4$ \\
\hline \hline$\alpha$ & 0.36 & 0.36 & 0.36 \\
\hline$\gamma_{a}$ & 0.000131 & 0.001413 & -0.000824 \\
\hline$\gamma_{v}$ & 0.006760 & 0.005311 & 0.009438 \\
\hline$\beta$ & 0.995 & 0.992 & 0.998 \\
\hline$\delta$ & 0.0135 & 0.0131 & 0.0121 \\
\hline$\eta$ & 0.0034 & 0.0037 & 0.0030 \\
\hline$\mu$ & 0.0086 & 0.0091 & 0.0074 \\
\hline$\varphi_{a}$ & 4.67 & 4.59 & 4.83 \\
\hline$\varphi_{v}$ & -0.16 & -0.07 & -0.65 \\
\hline$\rho_{a}$ & 0.98 & 0.97 & 0.96 \\
\hline$\rho_{v 1}$ & 1.77 & 1.71 & -0.73 \\
\hline$\rho_{v 2}$ & -0.77 & -0.76 & 0.0045 \\
\hline$\sigma_{\xi_{a}}$ & 0.0073 & 0.0086 & 0.0023 \\
\hline$\sigma_{\xi_{v}}$ & 0.0033 & 0.0037 & $\{0.5,1,1.5,2\}$ \\
\hline$\nu$ & $\{0.5,1,1.5,2\}$ & $\{0.5,1,1.5,2\}$ & $\{29.73,9.22,6.24,5.13\}$ \\
\hline$B$ & $\{30.02,9.31,6.30,5.18\}$ & $\{30.21,9.36,6.34,5.21\}$ & \\
\hline \hline
\end{tabular}


The ability of our model to account for the US business cycle features is sensitive to the value of the parameter governing the Frisch elasticity of labor supply. Tables 7, 8, 9, and 10 in appendix B report our results for the grid over $\nu$.

The deterministic trend model, however, is able to account for some relevant features of US business cycles irrespective of our choice for $\nu$. In particular, the model accounts for the large fluctuations of investment compared to output, for the small fluctuations of capital compared to output, and the relatively small fluctuations of hours compared to output.

The volatilities of investment (in efficiency units), output, capital (in efficiency units), and hours are increasing with the short-run elasticity of labor supply ${ }^{12}$. The standard deviation of hours implied by the model is smaller than the standard deviation of labor productivity which is at odds with the data. This is, however, a typical feature of RBC models with utility non-linear in hours. Hansen (1997)'s deterministic trend model was able to account for the pattern in the data by assuming that labor is indivisible and that agents trade employment lotteries $^{13}$.

The trend stationary model generates too much volatility in consumption in the first subsample for any value of the Frisch elasticity. For $\nu=1.5$ or $\nu=2$, the model implies volatilities for investment and capital for the pre-1984 sample that are too large.

Finally, this statistical version of our baseline RBC model cannot generate enough correlation between output and consumption. It generates, however, a large correlation between labor productivity and output that is at odds with the data. Moreover, the model cannot account for the change in sign in such a correlation in the second sub-sample.

\footnotetext{
${ }^{12}$ See Appendix G for the results when $\nu=\infty$

${ }^{13}$ The results under this assumptions for our model are reported in appendix G. We conclude that if the stochastic processes are trend stationary, a model à la Hansen overstates the volatilities of investment, output, capital, and hours. In such a setting, a model economy with only an investment-specific technology shock is able to replicate the volatility of hours. Finally, we also conclude that under a difference stationary framework our model economy is still not able to generate enough volatility for all the variables at hand.
} 


\subsection{Stochastic Growth Model}

\subsubsection{Random Walk with Drift}

Following King, Plosser, and Rebelo (1988) when addressing the difference stationary specification, we restrict our attention to the following class of parametric forms

$$
\Phi(L)(1-L) \log \left(X_{t}\right)=\gamma_{x}+\Theta(L) \varepsilon_{x t}
$$

where $\Phi(L)$ and $\Theta(L)$ are lag polynomials whose roots are outside the unit circle. The statistical model to be consider in this section is as follows

$$
\begin{aligned}
\ln A_{t} & =\ln A_{t-1}+\gamma_{a}+\varepsilon_{a t} \\
\ln V_{t} & =\ln V_{t-1}+\gamma_{v}+\varepsilon_{v t}
\end{aligned}
$$

which can be rewritten as

$$
\begin{aligned}
& \ln A_{t}=\ln A_{0}+\gamma_{a} t+\sum_{i=0}^{t} \varepsilon_{a t-i} \\
& \ln V_{t}=\ln V_{0}+\gamma_{v} t+\sum_{i=0}^{t} \varepsilon_{v t-i}
\end{aligned}
$$

Note that any shock to the stochastic trend at time $t$ has a permanent effect in the loglevel of the technology processes. Therefore, we are abstracting from transitory shocks in this specification which implies that we are just analyzing a lower bound of the effects of technology shocks.

Following Fisher (2006) and Fernández-Villaverde and Rubio-Ramírez (2006) we will assume

$$
\left(\begin{array}{c}
\varepsilon_{a t} \\
\varepsilon_{v t}
\end{array}\right) \sim \mathcal{N}\left[\left(\begin{array}{l}
0 \\
0
\end{array}\right), \mathbf{D}\right]
$$

where $\mathbf{D}$ is a diagonal matrix i.e.

$$
\mathbf{D}=\left(\begin{array}{cc}
\sigma_{a}^{2} & 0 \\
0 & \sigma_{v}^{2}
\end{array}\right)
$$

Our estimates are reported in table 3. Under this specification we also observe a reduction in the volatility of the innovations to the technology shocks of about $48 \%$.

In this version of the baseline RBC model, our calibration targets are identical to the ones in the previous subsection. The calibrated parameters are given in the following table: 
Table 3: Baseline Stochastic Trend: Calibrated Parameters

\begin{tabular}{|lc|c|c|}
\hline \hline & $1948: 1-2006: 4$ & $1948: 1-1983: 4$ & $1984: 1-2006: 4$ \\
\hline \hline$\alpha$ & 0.36 & 0.36 & 0.36 \\
\hline$\gamma_{a}$ & 0.000619 & 0.001489 & -0.000734 \\
\hline$\gamma_{v}$ & 0.00643 & 0.00493 & 0.008762 \\
\hline$\beta$ & 0.9894 & 0.9897 & 0.9889 \\
\hline$\delta$ & 0.01348 & 0.01401 & 0.01267 \\
\hline$\eta$ & 0.0034 & 0.0037 & 0.0030 \\
\hline$\mu$ & 0.92443 & 0.91670 & 0.93694 \\
\hline$\sigma_{a}$ & 0.0074 & 0.0087 & 0.0045 \\
\hline$\sigma_{v}$ & 0.0054 & 0.0060 & 0.0030 \\
\hline$\nu$ & $\{0.5,1,1.5,2\}$ & $\{0.5,1,1.5,2\}$ & $\{0.5,1,1.5,2\}$ \\
\hline$B$ & $\{30.02,9.31,6.30,5.18\}$ & $\{30.21,9.36,6.34,5.21\}$ & $\{29.73,9.22,6.24,5.13\}$ \\
\hline \hline
\end{tabular}

In tables 11, 12, 13, and 14 of appendix B, we report the results for the different values of the Frisch elasticity. The results for the volatility of output, investment, capital, and hours are also sensitive to the value of such a parameter. This statistical specification accounts for the same qualitative features of the US business cycle as the deterministic trend version.

The difference-stationary model does not overpredict the volatilities of consumption, investment, and capital. In fact, this statistical version of the model generates lower volatilities for all the variables than the trend stationary one.

In addition, the stochastic trend model is successful in accounting for the correlation of consumption and output. But it shares with the deterministic growth model the remaining unmatched features.

\subsubsection{Random Walk with Drift and Moving Average Component}

Following Christiano (1988) we will allow for a moving average component in the unit root specification for the investment-specific technology process. Thus, (46) will be substituted by

$$
\ln V_{t}=\ln V_{t-1}+\gamma_{v}+\rho \varepsilon_{v t-1}+\xi_{t}
$$


However, we will not modify our statistical specification for the neutral technology process since there is no evidence for the inclusion of a moving average component in such a representation.

Note that (47) allows for both temporary and permanent shocks. In particular, a fraction $1 /(1-\rho)$ of any innovation to the investment-specific shock will be permanent. The remainder will be temporary.

Our estimation results are reported in table 4. We also observe here a reduction in the volatility of the innovations to the technology shocks of about $56 \%$ for the investment-specific technology and $48 \%$ for the neutral one.

The results over the grid for the elasticity of labor supply with respect to real wage are reported in tables $15,16,17$, and 18 in appendix $\mathrm{B}$. This version of the stochastic trend model shares all the 'virtues' of the baseline stochastic growth model and improves upon some of its shortcomings. For example, volatilities of all the variables are larger than in the baseline case. However, this version of the stochastic growth model also generates too much correlation with output for consumption and labor productivity.

Table 4: Stochastic Trend with a Moving Average Component: Calibrated Parameters

\begin{tabular}{|lc|c|c|}
\hline \hline & $1948: 1-2006: 4$ & $1948: 1-1983: 4$ & $1984: 1-2006: 4$ \\
\hline \hline$\alpha$ & 0.36 & 0.36 & 0.36 \\
\hline$\gamma_{a}$ & 0.000619 & 0.001489 & -0.000734 \\
\hline$\gamma_{v}$ & 0.006404 & 0.004911 & 0.008739 \\
\hline$\beta$ & 0.9894 & 0.9897 & 0.9889 \\
\hline$\delta$ & 0.01352 & 0.01404 & 0.01271 \\
\hline$\eta$ & 0.0034 & 0.0037 & 0.0030 \\
\hline$\mu$ & 0.92439 & 0.91667 & 0.93692 \\
\hline$\rho$ & 0.618159 & 0.6359218 & 0.5071769 \\
\hline$\sigma_{a}$ & 0.0074 & 0.0087 & 0.0045 \\
\hline$\sigma_{v}$ & 0.0025 & 0.0028 & 0.0012 \\
\hline$\nu$ & $\{0.5,1,1.5,2\}$ & $\{0.5,1,1.5,2\}$ & $\{0.5,1,1.5,2\}$ \\
\hline$B$ & $\{30.02,9.31,6.30,5.18\}$ & $\{30.21,9.36,6.34,5.21\}$ & $\{29.73,9.22,6.24,5.13\}$ \\
\hline \hline
\end{tabular}




\subsection{Comparing Statistical Models}

From our previous analysis we can conclude that irrespective of the value for $\nu$, all the statistical models are able to qualitatively reproduce the slowdown in volatility. While the baseline difference-stationary model implies a reduction in the volatility of the variables at hand of about 50\%, the trend-stationary model overpredicts the slowdown for all the variables but output. Even though the baseline stochastic growth model outperforms the other two statistical specifications, it over predicts the slowdown in capital, hours, and labor productivity. The model implies a 50\% reduction while in the data we observe about a $35 \%$ slowdown.

To continue our analysis let us set the Frisch elasticity parameter equal to 1 . We have chosen such a value because of the better general performance of our statistical models for that value of the short-run elasticity of labor supply.

Table 5 reports how much volatility each model is able to account for. We observe that the trend-stationary model performs better than the difference-stationary models for the volatility of consumption, investment, output, and hours. However, the stochastic trend model with a moving average component outperforms the deterministic trend one in accounting for the standard deviation of labor productivity. It is also remarkable that the stochastic growth model with a moving average component performs relatively better than the baseline stochastic growth model. Therefore, we conclude that temporary shocks play a major role in business cycle accounting.

Table 5: $\nu=1: \sigma_{\text {model }} / \sigma_{\text {data }}$

\begin{tabular}{|l||c|c|c||c|c|c||c|c|c|}
\hline \multicolumn{1}{|c||}{} & \multicolumn{3}{l|}{$1948: 1-2006: 4$} & \multicolumn{3}{c|}{$1948: 1-1983: 4$} & \multicolumn{3}{c|}{$1984: 1-2006: 4$} \\
\cline { 2 - 10 } & DT & ST & ST-MA & DT & ST & ST-MA & DT & ST & ST-MA \\
\hline \hline $\mathrm{c}$ & 0.93 & 0.74 & 0.74 & 1.20 & 0.75 & 0.75 & 0.73 & 0.65 & 0.65 \\
\hline $\mathrm{x}$ & 0.76 & 0.49 & 0.50 & 0.98 & 0.47 & 0.50 & 0.66 & 0.48 & 0.46 \\
\hline $\mathrm{y}$ & 0.72 & 0.63 & 0.65 & 0.74 & 0.62 & 0.65 & 0.80 & 0.66 & 0.69 \\
\hline $\mathrm{k}$ & 0.90 & 0.47 & 0.98 & 1.07 & 0.47 & 1 & 0.60 & 0.48 & 0.64 \\
\hline $\mathrm{h}$ & 0.35 & 0.15 & 0.16 & 0.46 & 0.16 & 0.18 & 0.28 & 0.12 & 0.14 \\
\hline $\mathrm{y} / \mathrm{h}$ & 0.89 & 0.91 & 0.94 & 0.95 & 0.96 & 0.97 & 0.68 & 0.71 & 0.74 \\
\hline \hline
\end{tabular}


Let us also analyze the performance of the statistical specifications of our RBC model in terms of accounting for correlation with output. From table 6 we can conclude that the stochastic growth versions of our model account better for the correlation of all variables but labor productivity. However, as we concluded in the previous subsections, all the versions of the RBC model under analysis perform very poorly in matching the low correlation between output and labor productivity. Moreover, none of them is able to reproduce the change in sign we observe in the post-1984 period.

Hansen concluded that the deterministic growth model is the best one accounting for correlations of all the variables with output. Conversely, from our results we conclude that the stochastic growth model performs significantly better than the deterministic growth one.

Table 6: $\nu=1: \rho_{\text {model }} / \rho_{\text {data }}$

\begin{tabular}{|l||c|c|c||c|c|c||c|c|c|}
\hline \multicolumn{1}{|c||}{} & \multicolumn{3}{c|}{$1948: 1-2006: 4$} & \multicolumn{2}{c|}{$1948: 1-1983: 4$} & \multicolumn{2}{c|}{$1984: 1-2006: 4$} \\
\cline { 2 - 10 } & DT & ST & ST-MA & DT & ST & ST-MA & DT & ST & ST-MA \\
\hline \hline $\mathrm{c}$ & 0.28 & 1.13 & 1.13 & 0.05 & 1.15 & 1.12 & 0.25 & 0.99 & 1.16 \\
\hline $\mathrm{x}$ & 0.89 & 0.96 & 0.99 & 0.89 & 0.97 & 0.98 & 0.92 & 1.19 & 1.01 \\
\hline $\mathrm{y}$ & 1 & 1 & 1 & 1 & 1 & 1 & 1 & 1 & 1 \\
\hline $\mathrm{k}$ & 0.92 & 0.86 & 0.94 & 0.85 & 0.79 & 0.90 & 1.22 & 1.19 & 1.15 \\
\hline $\mathrm{h}$ & 0.90 & 0.97 & 0.98 & 0.87 & 0.98 & 0.98 & 0.93 & 0.94 & 1.01 \\
\hline $\mathrm{y} / \mathrm{h}$ & 7.91 & 8.91 & 8.90 & 3.39 & 4.26 & 4.26 & -1.93 & -2.13 & -2.15 \\
\hline \hline
\end{tabular}

Given the above, choosing one specification over the others depends upon what we are attempting to explain. If we were interested in matching volatilities we would choose, as Hansen (1997), the deterministic growth model. If we wanted to match correlations, we would choose a stochastic growth model. Finally, if we wanted to match the magnitude of the volatility slowdown in the 1980s, we would also choose a stochastic growth model.

\section{The Great Moderation}

So far we have performed our analysis allowing for changes in the structural parameters over the two subsamples of interest. In such a way we have shown that any of the statistical 
versions of our RBC model is able to account for a slowdown in macro volatilities. However, we are more interested in analyzing that part of the performance of our model due only to 'good luck'.

Thus, to better assess the relative importance of each technology shock in explaining the Great Moderation, we will perform some counterfactuals in the spirit of the ones performed by Arias, Hansen, and Ohanian (2007). In particular, we will proceed with three experiments. For all of them we will calibrate the parameters of the model to match the targets for the whole sample (i.e., we will fix them equal to the first column of tables 2,3 , and 4 ).

In the first counterfactual we will analyze the explicative power of the neutral technology shock. To do so, we will set the volatility of the innovation to the investment-specific technology to match its volatility for the entire sample. Therefore, the only time-varying parameter is the standard deviation of the neutral innovation. The second counterfactual is analogous to the first one but we focus on the investment-specific technology shock. Finally, in the third counterfactual we explore the explicative power of both shocks jointly by letting their standard deviations vary across subsamples.

The results for the first experiment are reported in table 19 of appendix C. We observe that while the stochastic growth models can reproduce a large fraction of the slowdown observed in the data, the trend-stationary model does only an acceptable job of accounting for the slowdown in output and labor productivity volatilities. Our main conclusion from this experiment is that smaller neutral technology innovations suffice to explain a large proportion of the aggregate stability observed in the mid 1980s if the model economy is difference stationary.

Table 20 in appendix $\mathrm{C}$ presents the results of the second counterfactual. We conclude that the role of the investment-specific shock as a single actor is greatly reduced. For example, for the deterministic trend case we have that although the investment-specific shock is $62 \%$ as volatile in the second subperiod as the first, this has a very small effect on the volatility of all the endogenous variables. In fact, it implies only a $2 \%$ slowdown in output volatility. We get similar results for the stochastic growth models.

Finally, table 21 reports the results for the third experiment. Under this scenario we can quantify the relative importance of the interaction between the two shocks active in our model economy. Here all the models are able to imply volatility slowdowns relatively similar to the ones in the data. 
We conclude that while the neutral shock is the main driving force in the slowdown in volatilities generated by our model, allowing for a larger financial flexibility substantially improves its ability to reproduce the magnitude of the observed slowdown in macro variability for the US economy. Therefore, the Great Moderation in our setting is not due only to 'good luck' but also to the interaction between the two technology shocks.

We have shown that an economy with only technology shocks is able to reproduce almost perfectly the slowdown in the standard deviation of consumption, investment, and output. However, such an economy cannot completely account for the magnitude of the reduction in the volatility of capital, hours, and labor productivity. In particular, all statistical specifications of our model economy overstate the mildness of such variables.

\section{Conclusion}

We have shown that the choice of the statistical model for the stochastic processes in an RBC model with two technology shocks is not a trivial one. In fact, one model would be preferred to the others depending on the features of the business cycle the researcher wants to match.

We have concluded that even though the neutral technology shock is the main driving force in replicating the Great Moderation, having two technology shocks translates into a better accounting for such a macroeconomic phenomenon. Therefore, the cross effects seem to be relevant. However, a bivariate specification of the innovations to the technology processes does not translate into a significative improvement of the performance of the model under analysis(see appendix $\mathrm{G}$ ).

Our model is not able to account for the slowdown in the volatilities of capital, hours, and labor productivity. In addition, the performance of our model for all the statistical specifications worsens for the post-1984 subsample both in terms of volatilities and correlations. In particular, none of our models is able to capture the change in sign for the correlation between output and labor productivity. It would be interesting to perform the present analysis with a model rich enough to address the shortcomings of this paper. 


\section{References}

Ahmed, S., A. Levin, And B. A. Wilson (2004): "Recent US Macroeconomic Stability: Good Policies, Good Practices, or Good Luck?," Review of Economics and Statistics, 86(3), 824-832.

Arias, A., G. D. Hansen, and L. E. Ohanian (2007): "Why Have Business Cycle Fluctuations Become Less Volatile?," Economic Theory, Forthcoming.

Beveridge, S., And C. Nelson (1981): "A new approach to decomposition of economic time series into permanent and transitory components with particular attention to measurement of the 'business cycle'," Journal of Monetary Economics, 7, 151-174.

Blanchard, O., and J. Simon (2001): "The long and large decline in U.S. output volatility," Brookings Papers on Economic Activity, 1, 135-164.

Burnside, C., and M. Eichenbaum (1996): "Factor-Hoarding and the Propagation of Business-Cycles Shocks," The American Economic Review, 86(5), 1154-1174.

Campbell, J. R., and Z. Hercowitz (2005): "The Role of Collateralized Household Debt in Macroeconomic Stabilization," Working Paper, Federal Reserve Bank of Chicago.

Chang, Y., T. Doh, and F. Schorfheide (2007): "Non-stationary Hours in a DSGE Model," Journal of Money, Credit, and Banking, Forthcoming.

Chari, V., P. J. Kehoe, and E. McGrattan (2004): "Business Cycle Accounting," NBER Working Paper No. 10351.

Christiano, L. J. (1988): "Why does inventory investment fluctuate so much?," Journal of Monetary Economics, 21, 247-280.

Christiano, L. J., M. Eichenbaum, and R. Vigfusson (2003): "What happens after a technology shock?," NBER Working Paper 9819.

Cooley, T. F., and E. C. Prescott (1995): "Economic Growth and Business Cycle," in Frontiers of Business Cycle Research, ed. by T. F. Cooley, chap. 1. Princeton University Press, Princeton. 
Dynan, K. E., D. W. Elmendorf, and D. E. Sichel (2005): "Can Financial Innovation Help to Explain the Reduced Volatility of Economic Activity?" Finance and Economics Discussion Series Divisions of Research \& Statistics and Monetary Affairs Federal Reserve Board, Washington, D.C.

(2006): "Financial Innovation and the Great Moderation: What Do Household Data Say?," Mimeo.

Fernández-Villaverde, J., and J. F. Rubio-Ramírez (2006): "Estimating Macroeconomic Models: A Likelihood Approach," Mimeo, Duke University.

Fisher, J. D. (2006): "The Dynamic Effects of Neutral and Investment-Specific Technology Shocks," Journal of Political Economy, 114(3), 413-451.

Galí, J. (1999): "Technology, Employment, and the Business Cycle: Do Technology Shocks Explain Aggregate Fluctuations?," The American Economic Review, 89(1), 249-271.

Galí, J., And P. Rabanal (2004): "Technology Shocks and Aggregate Fluctuations: How Well Does the Real Business Cycle Model Fit Postwar US Data?," IMF Working Paper $\mathrm{WP} / 04 / 234$.

Gomme, P., And P. Rupert (2007): "Theory, Measurement, and Calibration of Macroeconomic Models," Journal of Monetary Economics, 54, 460-497.

Greenwood, J., Z. Hercowitz, and P. Krusell (1997): "Long-Run Implications of Investment-Specific Technological Change," The American Economic Review, 83, 342-362.

- (2000): "The role of investment-specific technological change in the business cycle," European Economic Review, 44, 91-115.

Guerron, P. A. (2006): "Financial Innovations: An Alternative Explanation to the Great Moderation," Mimeo.

Hamilton, J. D. (1994): Time Series Analysis. Princeton University Press.

Hansen, G. D. (1997): "Technical progress and aggregate fluctuations," Journal of Economic Dynamics and Control, 21, 1005-1023. 
Jermann, U., and V. Quadrini (2006): "Financial Innovations and Macroeconomic Volatility," NBER Working Paper 12308.

Justiniano, A., and G. E. Primiceri (2006): "The time varying volatility of macroeconomic fluctuations," NBER Working Paper 12022.

Kahn, J. A., M. M. McConnell, and G. Pérez-Quirós (2002): "On the Causes of the Increased Stability of the U.S. Economy," Federal Reserve Bank of New York Economic Policy Review, 8(1), 183-202.

Kim, C.-J., J. C. Morley, and J. Piger (2004): "A Bayesian Approach to Counterfactual Analysis of Structural Change," FRB St Louis Working Paper No. 2004-014C.

Kim, C.-J., and C. R. Nelson (1999): "Has the U.S. Economy Become More Stable? A Bayesian Approach Based on a Markov-Switching Model of Business Cycle," Review of Economics and Statistics, 81(4), 608-616.

King, R. G., C. I. Plosser, and S. T. Rebelo (1988): "Production, Growth, and Business Cycles II. New Directions," Journal of Monetary Economics, 21, 309-341.

Leduc, S., And K. Sill (2006): "Monetary Policy, Oil Shocks, and TFP: Accounting for the Decline in U.S. Volatility," Board of Governors of the Federal Reserve System. International Finance Discussion Papers N. 873.

McConnell, M. M., And G. PÉRez-Quirós (2000): "Output fluctuations in the United States: what has changed since the early 1980's?," American Economic Review, 90(5), 1464-1476.

Nelson, C., And C. Plosser (1982): "Trends and random walks in macroeconomic time series: Some evidence and implications," Journal of Monetary Economics, 10, 139-162.

Prescott, E. C. (1986): "Response to a Skeptic," Quarterly Review. Minneapolis Federal Reserve Bank, 10, 28-33.

Stock, J. H., And M. W. Watson (2002): "Has the business cycle changed and why?," NBER Working Paper 9127. 


\section{A Balanced Growth Path}

From the feasibility constraint we can conclude that output, consumption, and investment grow at the same rate

$$
\begin{aligned}
Y_{t} & =C_{t}+I_{t} \\
\frac{Y_{t}}{Y_{t-1}} & =\frac{C_{t}}{C_{t-1}} \frac{C_{t-1}}{Y_{t-1}}+\frac{I_{t}}{I_{t-1}} \frac{I_{t-1}}{Y_{t-1}} \\
g_{Y} & =g_{C} \frac{C_{t-1}}{Y_{t-1}}+g_{I} \frac{I_{t-1}}{Y_{t-1}}
\end{aligned}
$$

Therefore, $g_{Y}$ is constant if and only if $g_{Y}=g_{C}=g_{I}$.

Let us consider now the investment equation

$$
\begin{aligned}
(1+\eta) K_{t+1} & =(1-\delta) K_{t}+V_{t} I_{t} \\
(1+\eta) \frac{K_{t+1}}{K_{t}} & =(1-\delta)+\frac{V_{t} I_{t}}{K_{t}} \\
(1+\eta) g_{K} & =(1-\delta)+\frac{V_{t} I_{t}}{K_{t}}
\end{aligned}
$$

$g_{K}$ is constant if and only if $(V I)$ grows at the same rate as $K$ which requires

$$
g_{K}=g_{I} g_{V}
$$

Let us analyze the production function

$$
\begin{aligned}
Y_{t} & =A_{t} K_{t}^{\alpha} H_{t}^{1-\alpha} \\
g_{Y} & =g_{A} g_{K}^{\alpha} g_{H}^{1-\alpha}
\end{aligned}
$$

As we are considering hours are stationary, we have that $g_{H}=1$. Hence,

$$
\begin{aligned}
g_{Y} & =g_{A} g_{K}^{\alpha} \\
& =g_{A}\left(g_{Y} g_{V}\right)^{\alpha}
\end{aligned}
$$

Therefore,

$$
g_{Y}=g_{A}^{\frac{1}{1-\alpha}} g_{V}^{\frac{\alpha}{1-\alpha}}
$$

Let us consider the deterministic growth model. We will have that

$$
\begin{aligned}
& g_{Y}=e^{\frac{1}{1-\alpha} \gamma_{a}+\frac{\alpha}{1-\alpha} \gamma_{v}} \\
& g_{V}=e^{\gamma_{v}}
\end{aligned}
$$


which implies

$$
g_{K}=e^{\frac{1}{1-\alpha}\left(\gamma_{a}+\gamma_{v}\right)}
$$

Let us consider the stochastic growth model. Then, we will have

$$
g_{Y}=A_{t}^{\frac{1}{1-\alpha}} V_{t}^{\frac{\alpha}{1-\alpha}}
$$

and

$$
g_{K}=A_{t}^{\frac{1}{1-\alpha}} V_{t}^{\frac{1}{1-\alpha}}
$$

\section{B Calibration: Results}


Table 7: Deterministic Trend: $\nu=0.5$

\begin{tabular}{|lcccc|cccc|ccccc|c|c|}
\hline \hline & \multicolumn{3}{|c|}{$1948: 1-2006: 4$} & \multicolumn{4}{c|}{$1948: 1-1983: 4$} & \multicolumn{5}{c|}{$1984: 1-2006: 4$} & \multicolumn{2}{c|}{$\sigma_{\text {post }} / \sigma_{\text {pre }}$} \\
& $\% \sigma_{\text {data }}$ & $\rho_{\text {data }}$ & $\% \sigma_{\text {model }}$ & $\rho_{\text {model }}$ & $\% \sigma_{\text {data }}$ & $\rho_{\text {data }}$ & $\% \sigma_{\text {model }}$ & $\rho_{\text {model }}$ & $\% \sigma_{\text {data }}$ & $\rho_{\text {data }}$ & $\% \sigma_{\text {model }}$ & $\rho_{\text {model }}$ & Data & Model \\
\hline \hline $\mathrm{c}$ & 0.92 & 0.78 & 0.86 & 0.30 & 1.07 & 0.78 & 1.27 & 0.14 & 0.62 & 0.81 & 0.44 & 0.26 & 0.58 & 0.35 \\
\hline $\mathrm{x}$ & 5.77 & 0.89 & 3.97 & 0.74 & 6.85 & 0.89 & 5.92 & 0.71 & 3.47 & 0.92 & 2.04 & 0.81 & 0.51 & 0.35 \\
\hline $\mathrm{y}$ & 1.73 & 1 & 1.11 & 1 & 2.07 & 1 & 1.34 & 1 & 0.99 & 1 & 0.70 & 1 & 0.48 & 0.52 \\
\hline $\mathrm{k}$ & 0.59 & 0.36 & 0.48 & 0.31 & 0.68 & 0.39 & 0.65 & 0.32 & 0.44 & 0.27 & 0.23 & 0.31 & 0.65 & 0.35 \\
\hline $\mathrm{h}$ & 1.88 & 0.87 & 0.40 & 0.72 & 2.11 & 0.87 & 0.57 & 0.68 & 1.46 & 0.90 & 0.24 & 0.80 & 0.69 & 0.42 \\
\hline$y / h$ & 0.94 & 0.11 & 0.87 & 0.95 & 1.06 & 0.23 & 1.04 & 0.91 & 0.72 & -0.46 & 0.52 & 0.96 & 0.68 & 0.50 \\
\hline \hline
\end{tabular}


Table 8: Deterministic Trend: $\nu=1$

\begin{tabular}{|lcccc|cccc|cccc|c|c|}
\hline \hline & \multicolumn{3}{|c|}{$1948: 1-2006: 4$} & \multicolumn{3}{c|}{$1948: 1-1983: 4$} & \multicolumn{5}{c|}{$1984: 1-2006: 4$} & \multicolumn{2}{c|}{$\sigma_{\text {post }} / \sigma_{\text {pre }}$} \\
& $\% \sigma_{\text {data }}$ & $\rho_{\text {data }}$ & $\% \sigma_{\text {model }}$ & $\rho_{\text {model }}$ & $\% \sigma_{\text {data }}$ & $\rho_{\text {data }}$ & $\% \sigma_{\text {model }}$ & $\rho_{\text {model }}$ & $\% \sigma_{\text {data }}$ & $\rho_{\text {data }}$ & $\% \sigma_{\text {model }}$ & $\rho_{\text {model }}$ & Data & Model \\
\hline \hline $\mathrm{c}$ & 0.92 & 0.78 & 0.86 & 0.26 & 1.07 & 0.78 & 1.27 & 0.04 & 0.62 & 0.81 & 0.45 & 0.20 & 0.58 & 0.35 \\
\hline $\mathrm{x}$ & 5.77 & 0.89 & 4.40 & 0.79 & 6.85 & 0.89 & 6.69 & 0.79 & 3.47 & 0.92 & 2.30 & 0.85 & 0.51 & 0.34 \\
\hline $\mathrm{y}$ & 1.73 & 1 & 1.24 & 1 & 2.07 & 1 & 1.53 & 1 & 0.99 & 1 & 0.79 & 1 & 0.48 & 0.52 \\
\hline $\mathrm{k}$ & 0.59 & 0.36 & 0.53 & 0.33 & 0.68 & 0.39 & 0.73 & 0.33 & 0.44 & 0.27 & 0.26 & 0.33 & 0.65 & 0.35 \\
\hline $\mathrm{h}$ & 1.88 & 0.87 & 0.66 & 0.78 & 2.11 & 0.87 & 0.97 & 0.76 & 1.46 & 0.90 & 0.41 & 0.84 & 0.69 & 0.42 \\
\hline$y / h$ & 0.94 & 0.11 & 0.84 & 0.87 & 1.06 & 0.23 & 1.01 & 0.78 & 0.72 & -0.46 & 0.49 & 0.89 & 0.68 & 0.49 \\
\hline \hline
\end{tabular}

ธิ

Table 9: Deterministic Trend: $\nu=1.5$

\begin{tabular}{|lcccc|cccc|cccc|c|c|}
\hline \hline & \multicolumn{4}{c|}{$1948: 1-2006: 4$} & \multicolumn{4}{c|}{$1948: 1-1983: 4$} & \multicolumn{5}{c|}{$1984: 1-2006: 4$} & \multicolumn{2}{c|}{$\sigma_{\text {post }} / \sigma_{\text {pre }}$} \\
& $\% \sigma_{\text {data }}$ & $\rho_{\text {data }}$ & $\% \sigma_{\text {model }}$ & $\rho_{\text {model }}$ & $\% \sigma_{\text {data }}$ & $\rho_{\text {data }}$ & $\% \sigma_{\text {model }}$ & $\rho_{\text {model }}$ & $\% \sigma_{\text {data }}$ & $\rho_{\text {data }}$ & $\% \sigma_{\text {model }}$ & $\rho_{\text {model }}$ & Data & Model \\
\hline \hline $\mathrm{c}$ & 0.92 & 0.78 & 0.86 & 0.22 & 1.07 & 0.78 & 1.26 & 0.002 & 0.62 & 0.81 & 0.46 & 0.16 & 0.58 & 0.37 \\
\hline $\mathrm{x}$ & 5.77 & 0.89 & 4.72 & 0.82 & 6.85 & 0.89 & 7.21 & 0.83 & 3.47 & 0.92 & 2.48 & 0.87 & 0.51 & 0.34 \\
\hline $\mathrm{y}$ & 1.73 & 1 & 1.34 & 1 & 2.07 & 1 & 1.68 & 1 & 0.99 & 1 & 0.85 & 1 & 0.48 & 0.51 \\
\hline $\mathrm{k}$ & 0.59 & 0.36 & 0.57 & 0.34 & 0.68 & 0.39 & 0.79 & 0.33 & 0.44 & 0.27 & 0.27 & 0.34 & 0.65 & 0.34 \\
\hline $\mathrm{h}$ & 1.88 & 0.87 & 0.85 & 0.81 & 2.11 & 0.87 & 1.26 & 0.80 & 1.46 & 0.90 & 0.54 & 0.86 & 0.69 & 0.43 \\
\hline$y / h$ & 0.94 & 0.11 & 0.82 & 0.79 & 1.06 & 0.23 & 1.01 & 0.66 & 0.72 & -0.46 & 0.47 & 0.82 & 0.68 & 0.47 \\
\hline \hline
\end{tabular}


Table 10: Deterministic Trend: $\nu=2$

\begin{tabular}{|lcccc|cccc|ccccc|c|c|}
\hline \hline & \multicolumn{3}{c|}{$1948: 1-2006: 4$} & \multicolumn{4}{c|}{$1948: 1-1983: 4$} & \multicolumn{5}{c|}{$1984: 1-2006: 4$} & \multicolumn{2}{c|}{$\sigma_{\text {post }} / \sigma_{\text {pre }}$} \\
& $\% \sigma_{\text {data }}$ & $\rho_{\text {data }}$ & $\% \sigma_{\text {model }}$ & $\rho_{\text {model }}$ & $\% \sigma_{\text {data }}$ & $\rho_{\text {data }}$ & $\% \sigma_{\text {model }}$ & $\rho_{\text {model }}$ & $\% \sigma_{\text {data }}$ & $\rho_{\text {data }}$ & $\% \sigma_{\text {model }}$ & $\rho_{\text {model }}$ & Data & Model \\
\hline \hline $\mathrm{c}$ & 0.92 & 0.78 & 0.86 & 0.20 & 1.07 & 0.78 & 1.26 & -0.03 & 0.62 & 0.81 & 0.46 & 0.14 & 0.58 & 0.37 \\
\hline $\mathrm{x}$ & 5.77 & 0.89 & 4.99 & 0.85 & 6.85 & 0.89 & 7.60 & 0.85 & 3.47 & 0.92 & 2.64 & 0.89 & 0.51 & 0.35 \\
\hline $\mathrm{y}$ & 1.73 & 1 & 1.43 & 1 & 2.07 & 1 & 1.78 & 1 & 0.99 & 1 & 0.91 & 1 & 0.48 & 0.51 \\
\hline $\mathrm{k}$ & 0.59 & 0.36 & 0.60 & 0.34 & 0.68 & 0.39 & 0.83 & 0.34 & 0.44 & 0.27 & 0.29 & 0.34 & 0.65 & 0.35 \\
\hline $\mathrm{h}$ & 1.88 & 0.87 & 1.01 & 0.83 & 2.11 & 0.87 & 1.48 & 0.82 & 1.46 & 0.90 & 0.64 & 0.88 & 0.69 & 0.43 \\
\hline$y / h$ & 0.94 & 0.11 & 0.82 & 0.72 & 1.06 & 0.23 & 1.01 & 0.55 & 0.72 & -0.46 & 0.46 & 0.75 & 0.68 & 0.46 \\
\hline \hline
\end{tabular}

Table 11: Baseline Stochastic Trend: $\nu=0.5$

\begin{tabular}{|lcccc|cccc|ccccc|c|c|}
\hline \hline & \multicolumn{4}{|c|}{$1948: 1-2006: 4$} & \multicolumn{4}{c|}{$1948: 1-1983: 4$} & \multicolumn{4}{c|}{$1984: 1-2006: 4$} & \multicolumn{2}{c|}{$\sigma_{\text {post }} / \sigma_{\text {pre }}$} \\
& $\% \sigma_{\text {data }}$ & $\rho_{\text {data }}$ & $\% \sigma_{\text {model }}$ & $\rho_{\text {model }}$ & $\% \sigma_{\text {data }}$ & $\rho_{\text {data }}$ & $\% \sigma_{\text {model }}$ & $\rho_{\text {model }}$ & $\sigma_{\text {data }}$ & $\rho_{\text {data }}$ & $\% \sigma_{\text {model }}$ & $\rho_{\text {model }}$ & Data & Model \\
\hline \hline $\mathrm{c}$ & 0.92 & 0.78 & 0.67 & 0.89 & 1.07 & 0.78 & 0.78 & 0.90 & 0.62 & 0.81 & 0.40 & 0.90 & 0.58 & 0.51 \\
\hline $\mathrm{x}$ & 5.77 & 0.89 & 2.61 & 0.84 & 6.85 & 0.89 & 2.96 & 0.85 & 3.47 & 0.92 & 1.55 & 0.85 & 0.51 & 0.52 \\
\hline $\mathrm{y}$ & 1.73 & 1 & 1.04 & 1 & 2.07 & 1 & 1.21 & 1 & 0.99 & 1 & 0.62 & 1 & 0.48 & 0.51 \\
\hline $\mathrm{k}$ & 0.59 & 0.36 & 0.26 & 0.30 & 0.68 & 0.39 & 0.30 & 0.30 & 0.44 & 0.27 & 0.16 & 0.31 & 0.65 & 0.50 \\
\hline $\mathrm{h}$ & 1.88 & 0.87 & 0.18 & 0.82 & 2.11 & 0.87 & 0.20 & 0.83 & 1.46 & 0.90 & 0.10 & 0.83 & 0.69 & 0.50 \\
\hline$y / h$ & 0.94 & 0.11 & 0.90 & 0.99 & 1.06 & 0.23 & 1.05 & 0.99 & 0.72 & -0.46 & 0.53 & 0.99 & 0.68 & 0.50 \\
\hline \hline
\end{tabular}


Table 12: Baseline Stochastic Trend: $\nu=1$

\begin{tabular}{|lcccc|cccc|ccccc|c|}
\hline \hline & \multicolumn{3}{c|}{$1948: 1-2006: 4$} & \multicolumn{4}{c|}{$1948: 1-1983: 4$} & \multicolumn{5}{c|}{$1984: 1-2006: 4$} & \multicolumn{2}{c|}{$\sigma_{\text {post }} / \sigma_{\text {pre }}$} \\
& $\% \sigma_{\text {data }}$ & $\rho_{\text {data }}$ & $\% \sigma_{\text {model }}$ & $\rho_{\text {model }}$ & $\% \sigma_{\text {data }}$ & $\rho_{\text {data }}$ & $\% \sigma_{\text {model }}$ & $\rho_{\text {model }}$ & $\% \sigma_{\text {data }}$ & $\rho_{\text {data }}$ & $\% \sigma_{\text {model }}$ & $\rho_{\text {model }}$ & Data & Model \\
\hline \hline $\mathrm{c}$ & 0.92 & 0.78 & 0.68 & 0.88 & 1.07 & 0.78 & 0.80 & 0.90 & 0.62 & 0.81 & 0.40 & 0.89 & 0.58 & 0.50 \\
\hline $\mathrm{x}$ & 5.77 & 0.89 & 2.80 & 0.85 & 6.85 & 0.89 & 3.19 & 0.86 & 3.47 & 0.92 & 1.67 & 0.86 & 0.51 & 0.52 \\
\hline $\mathrm{y}$ & 1.73 & 1 & 1.09 & 1 & 2.07 & 1 & 1.29 & 1 & 0.99 & 1 & 0.65 & 1 & 0.48 & 0.50 \\
\hline $\mathrm{k}$ & 0.59 & 0.36 & 0.28 & 0.31 & 0.68 & 0.39 & 0.32 & 0.31 & 0.44 & 0.27 & 0.17 & 0.32 & 0.65 & 0.53 \\
\hline $\mathrm{h}$ & 1.88 & 0.87 & 0.29 & 0.84 & 2.11 & 0.87 & 0.33 & 0.85 & 1.46 & 0.90 & 0.17 & 0.85 & 0.69 & 0.52 \\
\hline$y / h$ & 0.94 & 0.11 & 0.86 & 0.98 & 1.06 & 0.23 & 1.02 & 0.98 & 0.72 & -0.46 & 0.51 & 0.98 & 0.68 & 0.50 \\
\hline \hline
\end{tabular}

Table 13: Baseline Stochastic Trend: $\nu=1.5$

\begin{tabular}{|lcccc|cccc|cccc|c|c|}
\hline \hline & \multicolumn{3}{|c|}{$1948: 1-2006: 4$} & \multicolumn{4}{c|}{$1948: 1-1983: 4$} & \multicolumn{5}{c|}{$1984: 1-2006: 4$} & \multicolumn{2}{c|}{$\sigma_{\text {post }} / \sigma_{\text {pre }}$} \\
& $\% \sigma_{\text {data }}$ & $\rho_{\text {data }}$ & $\% \sigma_{\text {model }}$ & $\rho_{\text {model }}$ & $\% \sigma_{\text {data }}$ & $\rho_{\text {data }}$ & $\% \sigma_{\text {model }}$ & $\rho_{\text {model }}$ & $\% \sigma_{\text {data }}$ & $\rho_{\text {data }}$ & $\% \sigma_{\text {model }}$ & $\rho_{\text {model }}$ & Data & Model \\
\hline \hline $\mathrm{c}$ & 0.92 & 0.78 & 0.69 & 0.88 & 1.07 & 0.78 & 0.81 & 0.89 & 0.62 & 0.81 & 0.41 & 0.89 & 0.58 & 0.51 \\
\hline $\mathrm{x}$ & 5.77 & 0.89 & 2.96 & 0.87 & 6.85 & 0.89 & 3.33 & 0.87 & 3.47 & 0.92 & 1.75 & 0.87 & 0.51 & 0.53 \\
\hline $\mathrm{y}$ & 1.73 & 1 & 1.15 & 1 & 2.07 & 1 & 1.33 & 0.87 & 0.99 & 1 & 0.68 & 1 & 0.48 & 0.51 \\
\hline $\mathrm{k}$ & 0.59 & 0.36 & 0.29 & 0.31 & 0.68 & 0.39 & 0.33 & 0.31 & 0.44 & 0.27 & 0.17 & 0.32 & 0.65 & 0.52 \\
\hline $\mathrm{h}$ & 1.88 & 0.87 & 0.37 & 0.85 & 2.11 & 0.87 & 0.43 & 0.86 & 1.46 & 0.90 & 0.22 & 0.86 & 0.69 & 0.51 \\
\hline$y / h$ & 0.94 & 0.11 & 0.85 & 0.97 & 1.06 & 0.23 & 0.99 & 0.98 & 0.72 & -0.46 & 0.50 & 0.97 & 0.68 & 0.51 \\
\hline \hline
\end{tabular}


Table 14: Baseline Stochastic Trend: $\nu=2$

\begin{tabular}{|lcccc|cccc|cccc|c|c|}
\hline \hline & \multicolumn{3}{|c|}{$1948: 1-2006: 4$} & \multicolumn{4}{c|}{$1948: 1-1983: 4$} & \multicolumn{5}{c|}{$1984: 1-2006: 4$} & \multicolumn{2}{c|}{$\sigma_{\text {post }} / \sigma_{\text {pre }}$} \\
& $\% \sigma_{\text {data }}$ & $\rho_{\text {data }}$ & $\% \sigma_{\text {model }}$ & $\rho_{\text {model }}$ & $\% \sigma_{\text {data }}$ & $\rho_{\text {data }}$ & $\% \sigma_{\text {model }}$ & $\rho_{\text {model }}$ & $\% \sigma_{\text {data }}$ & $\rho_{\text {data }}$ & $\% \sigma_{\text {model }}$ & $\rho_{\text {model }}$ & Data & Model \\
\hline \hline $\mathrm{c}$ & 0.92 & 0.78 & 0.70 & 0.88 & 1.07 & 0.78 & 0.81 & 0.89 & 0.62 & 0.81 & 0.41 & 0.89 & 0.58 & 0.51 \\
\hline $\mathrm{x}$ & 5.77 & 0.89 & 3.04 & 0.87 & 6.85 & 0.89 & 3.47 & 0.88 & 3.47 & 0.92 & 1.82 & 0.88 & 0.51 & 0.52 \\
\hline $\mathrm{y}$ & 1.73 & 1 & 1.17 & 1 & 2.07 & 1 & 1.37 & 1 & 0.99 & 1 & 0.70 & 1 & 0.48 & 0.51 \\
\hline $\mathrm{k}$ & 0.59 & 0.36 & 0.30 & 0.32 & 0.68 & 0.39 & 0.35 & 0.32 & 0.44 & 0.27 & 0.18 & 0.32 & 0.65 & 0.51 \\
\hline $\mathrm{h}$ & 1.88 & 0.87 & 0.43 & 0.86 & 2.11 & 0.87 & 0.50 & 0.87 & 1.46 & 0.90 & 0.25 & 0.87 & 0.69 & 0.50 \\
\hline$y / h$ & 0.94 & 0.11 & 0.83 & 0.96 & 1.06 & 0.23 & 0.97 & 0.97 & 0.72 & -0.46 & 0.50 & 0.97 & 0.68 & 0.52 \\
\hline \hline
\end{tabular}

Table 15: Stochastic Trend with Moving Average Component: $\nu=0.5$

\begin{tabular}{|lcccc|cccc|ccccc|c|}
\hline \hline & \multicolumn{3}{c|}{$1948: 1-2006: 4$} & \multicolumn{4}{c|}{$1948: 1-1983: 4$} & \multicolumn{5}{c|}{$1984: 1-2006: 4$} & \multicolumn{2}{c|}{$\sigma_{\text {post }} / \sigma_{\text {pre }}$} \\
& $\% \sigma_{\text {data }}$ & $\rho_{\text {data }}$ & $\% \sigma_{\text {model }}$ & $\rho_{\text {model }}$ & $\% \sigma_{\text {data }}$ & $\rho_{\text {data }}$ & $\% \sigma_{\text {model }}$ & $\rho_{\text {model }}$ & $\% \sigma_{\text {data }}$ & $\rho_{\text {data }}$ & $\% \sigma_{\text {model }}$ & $\rho_{\text {model }}$ & Data & Model \\
\hline \hline $\mathrm{c}$ & 0.92 & 0.78 & 0.66 & 0.89 & 1.07 & 0.78 & 0.78 & 0.88 & 0.62 & 0.81 & 0.39 & 0.95 & 0.58 & 0.50 \\
\hline $\mathrm{x}$ & 5.77 & 0.89 & 2.64 & 0.86 & 6.85 & 0.89 & 3.09 & 0.86 & 3.47 & 0.92 & 1.46 & 0.92 & 0.51 & 0.47 \\
\hline $\mathrm{y}$ & 1.73 & 1 & 1.06 & 1 & 2.07 & 1 & 1.24 & 1 & 0.99 & 1 & 0.64 & 1 & 0.48 & 0.52 \\
\hline $\mathrm{k}$ & 0.59 & 0.36 & 0.60 & 0.32 & 0.68 & 0.39 & 0.66 & 0.32 & 0.44 & 0.27 & 0.27 & 0.30 & 0.65 & 0.41 \\
\hline $\mathrm{h}$ & 1.88 & 0.87 & 0.19 & 0.84 & 2.11 & 0.87 & 0.22 & 0.83 & 1.46 & 0.90 & 0.10 & 0.91 & 0.69 & 0.45 \\
\hline$y / h$ & 0.94 & 0.11 & 0.91 & 0.99 & 1.06 & 0.23 & 1.06 & 0.99 & 0.72 & -0.46 & 0.55 & 0.99 & 0.68 & 0.52 \\
\hline \hline
\end{tabular}


Table 16: Stochastic Trend with Moving Average Component: $\nu=1$

\begin{tabular}{|lcccc|cccc|ccccc|c|}
\hline \hline & \multicolumn{3}{|c|}{$1948: 1-2006: 4$} & \multicolumn{4}{c|}{$1948: 1-1983: 4$} & \multicolumn{5}{c|}{$1984: 1-2006: 4$} & \multicolumn{2}{c|}{$\sigma_{\text {post }} / \sigma_{\text {pre }}$} \\
& $\% \sigma_{\text {data }}$ & $\rho_{\text {data }}$ & $\% \sigma_{\text {model }}$ & $\rho_{\text {model }}$ & $\% \sigma_{\text {data }}$ & $\rho_{\text {data }}$ & $\% \sigma_{\text {model }}$ & $\rho_{\text {model }}$ & $\% \sigma_{\text {data }}$ & $\rho_{\text {data }}$ & $\% \sigma_{\text {model }}$ & $\rho_{\text {model }}$ & Data & Model \\
\hline \hline $\mathrm{c}$ & 0.92 & 0.78 & 0.68 & 0.88 & 1.07 & 0.78 & 0.80 & 0.87 & 0.62 & 0.81 & 0.40 & 0.94 & 0.58 & 0.50 \\
\hline $\mathrm{x}$ & 5.77 & 0.89 & 2.87 & 0.88 & 6.85 & 0.89 & 3.37 & 0.87 & 3.47 & 0.92 & 1.58 & 0.93 & 0.51 & 0.47 \\
\hline $\mathrm{y}$ & 1.73 & 1 & 1.12 & 1 & 2.07 & 1 & 1.33 & 1 & 0.99 & 1 & 0.68 & 1 & 0.48 & 0.51 \\
\hline $\mathrm{k}$ & 0.59 & 0.36 & 0.58 & 0.34 & 0.68 & 0.39 & 0.68 & 0.35 & 0.44 & 0.27 & 0.28 & 0.31 & 0.65 & 0.41 \\
\hline $\mathrm{h}$ & 1.88 & 0.87 & 0.31 & 0.85 & 2.11 & 0.87 & 0.37 & 0.85 & 1.46 & 0.90 & 0.16 & 0.91 & 0.69 & 0.43 \\
\hline$y / h$ & 0.94 & 0.11 & 0.88 & 0.98 & 1.06 & 0.23 & 1.03 & 0.98 & 0.72 & -0.46 & 0.53 & 0.99 & 0.68 & 0.51 \\
\hline \hline
\end{tabular}

Table 17: Stochastic Trend with Moving Average Component: $\nu=1.5$

\begin{tabular}{|lcccc|cccc|cccc|c|c|}
\hline \hline & \multicolumn{3}{|c|}{$1948: 1-2006: 4$} & \multicolumn{4}{c|}{$1948: 1-1983: 4$} & \multicolumn{5}{c|}{$1984: 1-2006: 4$} & \multicolumn{2}{c|}{$\sigma_{\text {post }} / \sigma_{\text {pre }}$} \\
& $\% \sigma_{\text {data }}$ & $\rho_{\text {data }}$ & $\% \sigma_{\text {model }}$ & $\rho_{\text {model }}$ & $\% \sigma_{\text {data }}$ & $\rho_{\text {data }}$ & $\% \sigma_{\text {model }}$ & $\rho_{\text {model }}$ & $\% \sigma_{\text {data }}$ & $\rho_{\text {data }}$ & $\% \sigma_{\text {model }}$ & $\rho_{\text {model }}$ & Data & Model \\
\hline \hline $\mathrm{c}$ & 0.92 & 0.78 & 0.69 & 0.87 & 1.07 & 0.78 & 0.81 & 0.86 & 0.62 & 0.81 & 0.41 & 0.94 & 0.58 & 0.51 \\
\hline $\mathrm{x}$ & 5.77 & 0.89 & 3.06 & 0.88 & 6.85 & 0.89 & 3.57 & 0.88 & 3.47 & 0.92 & 1.65 & 0.93 & 0.51 & 0.46 \\
\hline $\mathrm{y}$ & 1.73 & 1 & 1.18 & 1 & 2.07 & 1 & 1.38 & 1 & 0.99 & 1 & 0.70 & 1 & 0.48 & 0.51 \\
\hline $\mathrm{k}$ & 0.59 & 0.36 & 0.60 & 0.36 & 0.68 & 0.39 & 0.70 & 0.36 & 0.44 & 0.27 & 0.29 & 0.32 & 0.65 & 0.41 \\
\hline $\mathrm{h}$ & 1.88 & 0.87 & 0.40 & 0.86 & 2.11 & 0.87 & 0.48 & 0.86 & 1.46 & 0.90 & 0.21 & 0.92 & 0.69 & 0.44 \\
\hline$y / h$ & 0.94 & 0.11 & 0.86 & 0.97 & 1.06 & 0.23 & 1 & 0.97 & 0.72 & -0.46 & 0.51 & 0.99 & 0.68 & 0.51 \\
\hline \hline
\end{tabular}


Table 18: Stochastic Trend with Moving Average Component: $\nu=2$

\begin{tabular}{|c|c|c|c|c|c|c|c|c|c|c|c|c|c|c|}
\hline & \multicolumn{4}{|c|}{ 1948:1-2006:4 } & \multicolumn{4}{|c|}{ 1948:1-1983:4 } & \multicolumn{4}{|c|}{ 1984:1-2006:4 } & \multicolumn{2}{|c|}{$\sigma_{\text {post }} / \sigma_{\text {pre }}$} \\
\hline & $\% \sigma_{\text {data }}$ & $\rho_{\text {data }}$ & $\% \sigma_{\text {model }}$ & $\rho_{\text {model }}$ & $\% \sigma_{\text {data }}$ & $\rho_{\text {data }}$ & $\% \sigma_{\text {model }}$ & $\rho_{\text {model }}$ & $\% \sigma_{d a t a}$ & $\rho_{\text {data }}$ & $\% \sigma_{\text {model }}$ & $\rho_{\text {model }}$ & Data & Model \\
\hline $\mathrm{c}$ & 0.92 & 0.78 & 0.70 & 0.86 & 1.07 & 0.78 & 0.82 & 0.85 & 0.62 & 0.81 & 0.41 & 0.94 & 0.58 & 0.50 \\
\hline y & 1.73 & 1 & 1.21 & 1 & 2.07 & 1 & 1.42 & 1 & 0.99 & 1 & 0.72 & 1 & 0.48 & 0.51 \\
\hline $\mathrm{k}$ & 0.59 & 0.36 & 0.61 & 0.37 & 0.68 & 0.39 & 0.71 & 0.37 & 0.44 & 0.27 & 0.29 & 0.32 & 0.65 & 0.41 \\
\hline$y / h$ & 0.94 & 0.11 & 0.84 & 0.96 & 1.06 & 0.23 & 0.98 & 0.96 & 0.72 & -0.46 & 0.51 & 0.98 & 0.68 & 0.52 \\
\hline
\end{tabular}




\section{The Great Moderation: Experiments}

Table 19: Experiment 1

\begin{tabular}{|lccc|ccc|ccc|c|}
\hline \hline & \multicolumn{3}{c}{$\mathrm{DT}$} & \multicolumn{4}{c|}{$\mathrm{ST}$} & \multicolumn{4}{c|}{ ST-MA } & Data \\
& $\% \sigma_{\text {pre }}$ & $\% \sigma_{\text {post }}$ & $\sigma_{\text {pre }} / \sigma_{\text {post }}$ & $\% \sigma_{\text {pre }}$ & $\% \sigma_{\text {post }}$ & $\sigma_{\text {pre }} / \sigma_{\text {post }}$ & $\% \sigma_{\text {pre }}$ & $\% \sigma_{\text {post }}$ & $\sigma_{\text {pre }} / \sigma_{\text {post }}$ & $\sigma_{\text {pre }} / \sigma_{\text {post }}$ \\
\hline \hline $\mathrm{c}$ & 0.91 & 0.79 & 0.88 & 0.79 & 0.47 & 0.59 & 0.75 & 0.41 & 0.54 & 0.58 \\
\hline $\mathrm{x}$ & 4.74 & 3.90 & 0.82 & 3.13 & 2.19 & 0.70 & 2.80 & 1.64 & 0.59 & 0.51 \\
\hline $\mathrm{y}$ & 1.45 & 0.83 & 0.57 & 1.28 & 0.70 & 0.54 & 1.29 & 0.68 & 0.53 & 0.48 \\
\hline $\mathrm{k}$ & 0.57 & 0.50 & 0.88 & 0.31 & 0.22 & 0.71 & 0.38 & 0.30 & 0.79 & 0.65 \\
\hline $\mathrm{h}$ & 0.70 & 0.59 & 0.84 & 0.33 & 0.23 & 0.69 & 0.30 & 0.18 & 0.59 & 0.69 \\
\hline$y / h$ & 0.98 & 0.55 & 0.56 & 1.01 & 0.55 & 0.54 & 1.01 & 0.53 & 0.52 & 0.68 \\
\hline \hline
\end{tabular}

Table 20: Experiment 2

\begin{tabular}{|lccc|ccc|ccc|c|}
\hline \hline & \multicolumn{3}{c|}{$\mathrm{DT}$} & \multicolumn{4}{c|}{$\mathrm{ST}$} & \multicolumn{4}{c|}{ ST-MA } & Data \\
& $\% \sigma_{\text {pre }}$ & $\% \sigma_{\text {post }}$ & $\sigma_{\text {pre }} / \sigma_{\text {post }}$ & $\% \sigma_{\text {pre }}$ & $\% \sigma_{\text {post }}$ & $\sigma_{\text {pre }} / \sigma_{\text {post }}$ & $\% \sigma_{\text {pre }}$ & $\% \sigma_{\text {post }}$ & $\sigma_{\text {pre }} / \sigma_{\text {post }}$ & $\sigma_{\text {pre }} / \sigma_{\text {post }}$ \\
\hline \hline $\mathrm{c}$ & 0.94 & 0.87 & 0.92 & 0.70 & 0.65 & 0.93 & 0.69 & 0.65 & 0.94 & 0.58 \\
\hline $\mathrm{x}$ & 4.78 & 4.44 & 0.93 & 2.93 & 2.49 & 0.83 & 3.05 & 2.44 & 0.80 & 0.51 \\
\hline $\mathrm{y}$ & 1.26 & 1.24 & 0.98 & 1.10 & 1.09 & 0.99 & 1.14 & 1.10 & 0.97 & 0.48 \\
\hline $\mathrm{k}$ & 0.59 & 0.54 & 0.92 & 0.29 & 0.24 & 0.83 & 0.66 & 0.35 & 0.53 & 0.65 \\
\hline $\mathrm{h}$ & 0.72 & 0.66 & 0.92 & 0.31 & 0.26 & 0.84 & 0.33 & 0.26 & 0.78 & 0.69 \\
\hline$y / h$ & 0.85 & 0.84 & 0.98 & 0.87 & 0.86 & 0.98 & 0.88 & 0.87 & 0.98 & 0.68 \\
\hline \hline
\end{tabular}


Table 21: Experiment 3

\begin{tabular}{|c|c|c|c|c|c|c|c|c|c|c|}
\hline & \multicolumn{3}{|c|}{$\mathrm{DT}$} & \multicolumn{3}{|c|}{ ST } & \multicolumn{3}{|c|}{ ST-MA } & \multirow{2}{*}{$\begin{array}{c}\text { Data } \\
\sigma_{\text {pre }} / \sigma_{\text {post }}\end{array}$} \\
\hline & $\% \sigma_{\text {pre }}$ & $\% \sigma_{\text {post }}$ & $\sigma_{\text {pre }} / \sigma_{\text {post }}$ & $\% \sigma_{\text {pre }}$ & $\% \sigma_{\text {post }}$ & $\sigma_{\text {pre }} / \sigma_{\text {post }}$ & $\% \sigma_{\text {pre }}$ & $\% \sigma_{\text {post }}$ & $\sigma_{\text {pre }} / \sigma_{\text {post }}$ & \\
\hline $\mathrm{c}$ & 0.98 & 0.57 & 0.58 & 0.80 & 0.43 & 0.53 & 0.79 & 0.40 & 0.51 & 0.58 \\
\hline $\mathrm{x}$ & 5.07 & 2.90 & 0.57 & 3.23 & 1.71 & 0.53 & 3.35 & 1.64 & 0.49 & 0.51 \\
\hline $\mathrm{y}$ & 1.47 & 0.78 & 0.53 & 1.29 & 0.69 & 0.54 & 1.32 & 0.68 & 0.51 & 0.48 \\
\hline $\mathrm{k}$ & 0.62 & 0.36 & 0.59 & 0.32 & 0.17 & 0.53 & 0.68 & 0.30 & 0.45 & 0.65 \\
\hline $\mathrm{h}$ & 0.76 & 0.43 & 0.57 & 0.34 & 0.18 & 0.53 & 0.36 & 0.17 & 0.49 & 0.69 \\
\hline$y / h$ & 0.99 & 0.52 & 0.53 & 1.02 & 0.55 & 0.54 & 1.03 & 0.53 & 0.52 & 0.68 \\
\hline
\end{tabular}




\section{Log-linearization around the steady state}

\section{D.1 Deterministic Trend Model}

Let us define $\hat{x}_{t}=\ln \left(\tilde{X}_{t} / X^{*}\right)$, then the log-linearized system of equations is given by:

$$
\begin{aligned}
\hat{y}_{t} & =\frac{C^{*}}{Y^{*}} \hat{c}_{t}+\frac{I^{*}}{Y^{*}} \hat{i}_{t} \\
\hat{y}_{t} & =\alpha \hat{k}_{t}+(1-\alpha) \hat{h}_{t}+\varepsilon_{a t} \\
q v \hat{k}_{t+1} & =(1-\delta) \hat{k}_{t}+V_{0} \frac{I^{*}}{K^{*}}\left[e^{\varepsilon_{v t}}\left(1+\hat{i}_{t}\right)-1\right] \\
0 & =E_{t}\left[\hat{c}_{t}-\hat{c}_{t-1}+\varepsilon_{v t}-\varepsilon_{v t+1}+\left(\frac{R^{*}}{1-\delta+R^{*}}\right) \hat{r}_{t+1}\right] \\
\hat{h}_{t} & =\nu\left(\hat{w}_{t}-\hat{c}_{t}-\hat{b}_{t}\right) \\
\hat{r}_{t} & =\hat{y}_{t}-\hat{k}_{t}+\varepsilon_{v t} \\
\hat{w}_{t} & =\hat{y}_{t}-\hat{h}_{t}
\end{aligned}
$$

\section{D.2 Stochastic Trend Model}

Let us define $\hat{x}_{t}=\ln \left(\tilde{X}_{t} / X^{*}\right)$, then the log-linearized system of equations is given by:

$$
\begin{aligned}
\hat{y}_{t} & =\hat{c}_{t} \frac{C^{*}}{Y^{*}}+\hat{i}_{t} \frac{I^{*}}{Y^{*}} \\
\hat{y}_{t} & =-\alpha\left(\hat{q}_{t}+\hat{v}_{t}\right)+\alpha \hat{k}_{t}+(1-\alpha) \hat{h}_{t} \\
\hat{k}_{t+1} & =(1-\delta)\left(\frac{1}{q^{*} v^{*}}\right)\left[\hat{k}_{t}-\left(\hat{q}_{t}+\hat{v}_{t}\right)\right]+\hat{i}_{t} \frac{I^{*}}{K^{*}} \\
0 & \left.=E_{t}\left[\hat{c}_{t}-\hat{c}_{t-1}-\left(\hat{q}_{t+1}+\hat{v}_{t+1}\right)+\hat{r}_{t+1}^{k}\right]\right] \\
\hat{r_{t}^{k}} & =\left(\frac{R^{*}}{R^{k *}}\right) \hat{r}_{t} \\
\hat{h}_{t} & =\nu\left(\hat{w}_{t}-\hat{c}_{t} \hat{b}_{t}\right) \\
\hat{b}_{t} & =\rho_{b} \hat{b}_{t-1}+\varepsilon_{b t} \\
\hat{r}_{t} & =\hat{y}_{t}-\hat{k}_{t}+\hat{q}_{t}+\hat{v}_{t} \\
\hat{w}_{t} & =\hat{y}_{t}-\hat{h}_{t} \\
\hat{q}_{t} & =\frac{1}{1-\alpha} \varepsilon_{a t}+\frac{\alpha}{1-\alpha} \varepsilon_{v t} \\
\hat{v}_{t} & =\varepsilon_{v t}
\end{aligned}
$$


The above is a system of 11 equations and 11 unknowns: $\left\{\hat{c}_{t}, \hat{i}_{t}, \hat{y}_{t}, \hat{k}_{t}, \hat{h}_{t}, \hat{b}_{t}, \hat{r}_{t}, \hat{r}_{t}^{k}, \hat{q}_{t}, \hat{v}_{t},\right\}$. To proceed with estimation we need to also consider the following conditions:

$$
\begin{aligned}
q^{*} & =e^{\frac{1}{1-\alpha} \gamma_{a}+\frac{\alpha}{1-\alpha} \gamma_{v}} \\
v^{*} & =e^{\gamma_{v}} \\
R^{*} & =\frac{q^{*} v^{*}}{\beta}-(1-\delta) \\
R^{k *} & =(1-\delta)+R^{*}=\frac{q^{*} v^{*}}{\beta} \\
\frac{I^{*}}{K^{*}} & =1-(1-\delta) \frac{1}{q^{*} v^{*}} \\
\frac{K^{*}}{Y^{*}} & =\frac{1}{\alpha q^{*} v^{*}} R^{*} \\
\frac{C^{*}}{Y^{*}} & =\left(\frac{1-\delta}{q^{*} v^{*}}-1\right) \frac{K^{*}}{Y^{*}}+1 \\
\frac{I^{*}}{Y^{*}} & =1-\frac{C^{*}}{Y^{*}} \\
H^{*} & =\left(\frac{1}{B^{*}}\right)^{\frac{\nu}{1+\nu}}\left[(1-\alpha) \frac{Y^{*}}{C^{*}}\right]^{\frac{\nu}{1+\nu}}
\end{aligned}
$$




\section{E Figures}



Figure 1: Solow residual

\section{F The Great Moderation: Empirical Evidence}


Table 22: Variables used in the paper: Percentage Standard Deviations

\begin{tabular}{|lc|c|c|c|}
\hline \hline & $1948: 1-2006: 4$ & Pre-1984 & Post-1984 & $\sigma_{\text {post }} / \sigma_{\text {pre }}$ \\
\hline GNP & 1.73 & 2.07 & 0.99 & 0.48 \\
Consumption & 0.92 & 1.07 & 0.62 & 0.58 \\
Investment(efficiency units) & 5.77 & 6.85 & 3.47 & 0.51 \\
Capital(efficiency units) & 0.59 & 0.68 & 0.44 & 0.65 \\
Hours & 1.88 & 2.11 & 1.46 & 0.69 \\
Labor productivity & 0.94 & 1.06 & 0.72 & 0.68 \\
\hline \hline
\end{tabular}

Source:Ríos-Rull, Santaeulàlia, and Schorfheide Data Set. We have HP-filtered the log of real variables. 
Table 23: Real GDP and components

\begin{tabular}{lcc|cc|cc|c}
\hline \hline & \multicolumn{2}{c|}{$1950-2006$} & \multicolumn{2}{|c|}{ Pre-1984 } & \multicolumn{2}{|c|}{ Post-1984 } & Post/Pre \\
& $\% \sigma_{x}$ & $\rho(G D P, x)$ & $\% \sigma_{x}$ & $\rho(G D P, x)$ & $\% \sigma_{x}$ & $\rho(G D P, x)$ & \\
\hline \hline GDP & 1.62 & 1 & 1.96 & 1 & 0.92 & 1 & 0.47 \\
Personal consumption & 1.27 & 0.78 & 1.52 & 0.77 & 7.50 & 0.82 & 0.49 \\
$\quad$ Durable goods & 5.07 & 0.66 & 6.11 & 0.66 & 2.89 & 0.63 & 0.47 \\
$\quad$ Nondurable goods & 1.09 & 0.73 & 1.27 & 0.73 & 0.75 & 0.79 & 0.59 \\
$\quad$ Services & 0.69 & 0.70 & 0.75 & 0.72 & 0.57 & 0.65 & 0.76 \\
Gross Domestic Private Investment & 7.45 & 0.86 & 8.74 & 0.86 & 4.96 & 0.87 & 0.57 \\
$\quad$ Fixed Investment & 4.93 & 0.81 & 5.66 & 0.79 & 3.60 & 0.90 & 0.64 \\
$\quad$ Non residential & 4.84 & 0.75 & 5.23 & 0.75 & 4.22 & 0.84 & 0.81 \\
$\quad$ Structures & 5.01 & 0.47 & 4.84 & 0.48 & 5.27 & 0.59 & 1.09 \\
$\quad$ Equipment and Software & 5.43 & 0.81 & 6.10 & 0.81 & 4.23 & 0.87 & 0.69 \\
$\quad$ Residential & 9.58 & 0.54 & 11.61 & 0.55 & 5.30 & 0.48 & 0.46 \\
Exports & 5.19 & 0.38 & 6.13 & 0.36 & 3.38 & 0.52 & 0.55 \\
Imports & 4.95 & 0.69 & 5.83 & 0.67 & 3.21 & 0.79 & 0.55 \\
Government cons and inv & 3.51 & 0.15 & 4.46 & 0.18 & 1.07 & -0.17 & 0.24 \\
\hline
\end{tabular}

Source: Table 1.1.4 and 1.1.5 from NIPA. We have HP-filtered the log of the real variables. 
Table 24: Gross value added by sector

\begin{tabular}{lcc|cc|cc|c}
\hline \hline & \multicolumn{2}{c|}{$1950-2006$} & \multicolumn{2}{c|}{ Pre-1984 } & \multicolumn{2}{c|}{ Post-1984 } & Post/Pre \\
& $\% \sigma_{x}$ & $\rho(G D P, x)$ & $\% \sigma_{x}$ & $\rho(G D P, x)$ & $\% \sigma_{x}$ & $\rho(G D P, x)$ & \\
\hline \hline GDP & 1.62 & 1 & 1.96 & 1 & 0.92 & 1 & 0.47 \\
Business & 2.03 & 0.99 & 2.43 & 0.99 & 1.20 & 0.99 & 0.49 \\
$\quad$ Nonfarm & 2.16 & 0.99 & 2.61 & 0.99 & 1.21 & 0.99 & 0.46 \\
$\quad$ Farm & 9.48 & -0.08 & 9.71 & -0.14 & 9.16 & 0.095 & 0.94 \\
Households and Institutions & 0.79 & 0.07 & 0.76 & 0.04 & 0.83 & 0.17 & 1.09 \\
$\quad$ Households & 1.12 & 0.16 & 0.89 & 0.14 & 1.39 & 0.30 & 1.55 \\
$\quad$ Nonprofit institutions & 1.31 & -0.10 & 1.50 & -0.08 & 0.98 & -0.21 & 0.65 \\
General government & 1.59 & 0.18 & 2.02 & 0.22 & 0.49 & -0.30 & 0.24 \\
Housing & 1.05 & 0.04 & 0.71 & -0.05 & 1.4 & 0.22 & 2.00 \\
\hline \hline
\end{tabular}

Source: Table 1.3.4 and 1.3.5 from NIPA. We have HP-filtered the log of the real variables.

\section{G Extensions}

\section{G.1 Hansen-Rogerson Preferences}

So far our analysis have only considered the intensive margin of the labor input. Here we will assume another specification for household's preferences so that we will analyze the extensive margin of the labor input. To do so let us assume the following:

1. Labor is indivisible.

2. Agents can trade employment lotteries.

3. Households have a constant relative risk-aversion utility function with a coefficient of risk-aversion equal to 1.

Therefore, (2) will be substituted by

$$
U\left(C_{t}, H_{t}\right)=\ln C_{t}-B H_{t}
$$


which implies that the short-run Frisch elasticity of labor supply is infinite.

It is obvious that the (detrended) equilibrium conditions under all the statistical models are identical but the one associated with the labor supply. In particular, (15) and (29) will be substituted by

$$
\frac{\tilde{W}_{t}}{\tilde{C}_{t}}=B
$$

We need to recalibrate only the parameter linked to the weight of hours in the utility function i.e. B. In fact, we have that

$$
B=(1-\alpha) \frac{Y^{*}}{C^{*}} \frac{1}{H^{*}}
$$

We will stochastic simulate our model only for the deterministic trend case and the baseline stochastic trend one. We will perform our analysis only for the whole sample.

We will first allow for the presence of both technology shocks. Then, we will perform two counterfactuals in order to asses the relative importance of each technology shock in accounting for the business cycles features observed in the US data. On the one hand, we will shut down the investment specific shock and investigate the volatilities implied by our model. On the other hand, we will shut down the neutral shock and perform the same analysis.

Table 25: Deterministic Trend Model: 1948:1-2006:4

\begin{tabular}{|lcc|ccc|ccc|ccc|}
\hline \hline & \multicolumn{2}{c|}{ Data } & \multicolumn{4}{c|}{ Both shocks } & \multicolumn{3}{c|}{ Only N-shock } & \multicolumn{4}{c|}{ Only I-shock } \\
& $\% \sigma_{z}$ & $\rho_{z y}$ & $\% \sigma_{z}$ & $\rho_{z y}$ & $\sigma_{\text {model }} / \sigma_{\text {data }}$ & $\% \sigma_{z}$ & $\rho_{z y}$ & $\sigma_{\text {model }} / \sigma_{\text {data }}$ & $\% \sigma_{z}$ & $\rho_{z y}$ & $\sigma_{\text {model }} / \sigma_{\text {data }}$ \\
\hline \hline $\mathrm{c}$ & 0.92 & 0.78 & 0.89 & 0.08 & 0.97 & 0.55 & 0.94 & 0.60 & 0.70 & -0.84 & 0.76 \\
\hline $\mathrm{x}$ & 5.77 & 0.89 & 6.99 & 0.93 & 1.21 & 4.01 & 0.99 & 0.69 & 5.72 & 0.97 & 0.99 \\
\hline $\mathrm{y}$ & 1.73 & 1 & 2.07 & 1 & 1.20 & 1.68 & 1 & 0.97 & 1.21 & 1 & 0.70 \\
\hline $\mathrm{k}$ & 0.59 & 0.36 & 0.81 & 0.35 & 1.37 & 0.39 & 0.33 & 0.66 & 0.71 & 0.44 & 1.20 \\
\hline $\mathrm{h}$ & 1.88 & 0.87 & 2.19 & 0.91 & 1.16 & 1.18 & 0.99 & 0.63 & 1.84 & 0.98 & 0.98 \\
\hline$y / h$ & 0.94 & 0.11 & 0.89 & 0.08 & 0.95 & 0.55 & 0.94 & 0.59 & 0.70 & -0.84 & 0.74 \\
\hline \hline
\end{tabular}

From table G.1 we conclude that the volatilities of all the variables at hand are larger than in the divisible labor economy. Moreover, the Hansen-Rogerson economy overstates 
the volatilities of investment, output, capital, and hours when both shocks are at hand. It is remarkable that, as in Hansen (1997), the volatility of hours is larger than the volatility of labor productivity.

The model performs better, in terms of accounting for volatilities, when there is only an investment-specific shock than when there is only a neutral one. In fact, a model with Hansen-Rogerson preferences and only an I-shock is able to replicate almost perfectly the standard deviation of hours.

Table 26: Stochastic Trend Model: 1948:1-2006:4

\begin{tabular}{|lcc|ccc|ccc|ccc|}
\hline \hline & \multicolumn{2}{c|}{ Data } & \multicolumn{4}{c|}{ Both shocks } & \multicolumn{3}{c|}{ Only N-shock } & \multicolumn{4}{c|}{ Only I-shock } \\
& $\% \sigma_{z}$ & $\rho_{z y}$ & $\% \sigma_{z}$ & $\rho_{z y}$ & $\sigma_{\text {model }} / \sigma_{\text {data }}$ & $\% \sigma_{z}$ & $\rho_{z y}$ & $\sigma_{\text {model }} / \sigma_{\text {data }}$ & $\% \sigma_{z}$ & $\rho_{z y}$ & $\sigma_{\text {model }} / \sigma_{\text {data }}$ \\
\hline \hline $\mathrm{c}$ & 0.92 & 0.78 & 0.75 & 0.87 & 0.82 & 0.72 & 0.98 & 0.78 & 0.21 & -0.81 & 0.23 \\
\hline $\mathrm{x}$ & 5.77 & 0.89 & 3.80 & 0.91 & 0.66 & 3.08 & 0.99 & 0.53 & 2.23 & 0.99 & 0.39 \\
\hline $\mathrm{y}$ & 1.73 & 1 & 1.41 & 1 & 0.82 & 1.38 & 1 & 0.81 & 0.32 & 1 & 0.18 \\
\hline $\mathrm{k}$ & 0.59 & 0.36 & 0.37 & 0.33 & 0.63 & 0.30 & 0.35 & 0.51 & 0.22 & 0.38 & 0.37 \\
\hline $\mathrm{h}$ & 1.88 & 0.87 & 0.85 & 0.90 & 0.45 & 0.69 & 0.98 & 0.37 & 0.50 & 0.97 & 0.27 \\
\hline$y / h$ & 0.94 & 0.11 & 0.75 & 0.87 & 0.80 & 0.72 & 0.98 & 0.77 & 0.21 & -0.81 & 0.22 \\
\hline \hline
\end{tabular}

From the above table we conclude that a stochastic growth model is not able to generate enough volatility in this scenario either. Under this specification, the neutral shock is the one able to account for the bulk of the volatility for all the variables at hand.

\section{G.2 Multivariate Analysis}

We have performed univariate analysis of the error structure associated to the different specifications for the technology processes. We are interested here in exploring a multivariate error structure in order to analyze the interaction between both innovations.

\section{G.2.1 Deterministic Growth Model}

We will consider the following specification

$$
\ln A_{t}=\varphi_{a}+\gamma_{a} t+\varepsilon_{a t}
$$




$$
\ln V_{t}=\varphi_{v}+\gamma_{v} t+\varepsilon_{v t}
$$

and we assume

$$
\left(\begin{array}{c}
\varepsilon_{a t} \\
\varepsilon_{v t}
\end{array}\right)=\Gamma_{1}\left(\begin{array}{c}
\varepsilon_{a t-1} \\
\varepsilon_{v t-1}
\end{array}\right)+\Gamma_{2}\left(\begin{array}{c}
\varepsilon_{a t-2} \\
\varepsilon_{v t-2}
\end{array}\right)+\left(\begin{array}{c}
\xi_{a t} \\
\xi_{v t}
\end{array}\right)
$$

where

$$
\left(\begin{array}{l}
\xi_{a t} \\
\xi_{v t}
\end{array}\right) \sim \mathcal{N}\left(\mathbf{0}, \Sigma_{\xi}\right)
$$

We will restrict our attention to the performance of the model under a unit Frisch elasticity. Our estimates are reported in the following table. All the vector autoregressive processes estimated satisfy the stability condition i.e. there is no root that lies outside the unit circle.

Table 27: Deterministic Trend: Estimated Parameters

\begin{tabular}{|c|c|c|c|}
\hline \hline & $1948: 1-2006: 4$ & $1948: 1-1983: 4$ & $1984: 1-2006: 4$ \\
\hline \hline$\gamma_{a}$ & 0.000131 & 0.001413 & -0.000824 \\
\hline$\gamma_{v}$ & 0.006760 & 0.005311 & 0.009438 \\
\hline$\varphi_{a}$ & 4.67 & 4.59 & 4.83 \\
\hline$\varphi_{v}$ & -0.16 & -0.07 & -0.65 \\
\hline$\Gamma_{1}$ & $\left(\begin{array}{cc}0.999477^{*} & -0.200311^{*} \\
0.072667^{*} & 1.791754^{*}\end{array}\right)$ & $\left(\begin{array}{cc}1.032293^{*} & -0.161686 \\
0.051353^{*} & 1.735752^{*}\end{array}\right)$ & $\left(\begin{array}{cc}0.753032^{*} & -0.140866 \\
0.075780 & 1.635421^{*}\end{array}\right)$ \\
\hline$\Gamma_{2}$ & $\left(\begin{array}{cc}-0.022612 & 0.197971^{*} \\
-0.081605^{*} & -0.805428^{*}\end{array}\right)$ & $\left(\begin{array}{cc}-0.075576 & 0.122759 \\
-0.055663^{*} & -0.784986^{*}\end{array}\right)$ & $\left(\begin{array}{cc}0.201175^{*} & 0.170665 \\
-0.127270^{*} & -0.644031^{*}\end{array}\right)$ \\
\hline$\Sigma_{\xi}$ & $\left(\begin{array}{cc}5.22 \cdot 10^{-5} & -6.80 \cdot 10^{-6} \\
\cdot & 1.11 \cdot 10^{-5}\end{array}\right)$ & $\left(\begin{array}{cc}7.28 \cdot 10^{-5} & -9.98 \cdot 10^{-6} \\
\cdot & 1.40 \cdot 10^{-5}\end{array}\right)$ & $\left(\begin{array}{cc}1.98 \cdot 10^{-5} & -2.89 \cdot 10^{-6} \\
\cdot & 4.73 \cdot 10^{-6}\end{array}\right)$ \\
\hline \hline
\end{tabular}

The results obtained from the stochastic simulation of our model economy are summarized in the following table: 
Table 28: Deterministic Trend: Multivariate Analysis Results

\begin{tabular}{|lcccc|cccc|ccccc|c|}
\hline \hline & \multicolumn{3}{|c|}{$1948: 1-2006: 4$} & \multicolumn{5}{c|}{$1948: 1-1983: 4$} & \multicolumn{5}{c|}{$1984: 1-2006: 4$} & \multicolumn{2}{c|}{$\sigma_{\text {post }} / \sigma_{\text {pre }}$} \\
& $\% \sigma_{\text {data }}$ & $\rho_{\text {data }}$ & $\% \sigma_{\text {model }}$ & $\rho_{\text {model }}$ & $\% \sigma_{\text {data }}$ & $\rho_{\text {data }}$ & $\% \sigma_{\text {model }}$ & $\rho_{\text {model }}$ & $\% \sigma_{\text {data }}$ & $\rho_{\text {data }}$ & $\% \sigma_{\text {model }}$ & $\rho_{\text {model }}$ & Data & Model \\
\hline \hline $\mathrm{c}$ & 0.92 & 0.78 & 0.97 & 0.33 & 1.07 & 0.78 & 1.37 & 0.24 & 0.62 & 0.81 & 0.51 & -0.23 & 0.58 & 0.37 \\
\hline $\mathrm{x}$ & 5.77 & 0.89 & 4.26 & 0.71 & 6.85 & 0.89 & 5.99 & 0.69 & 3.47 & 0.92 & 2.87 & 0.88 & 0.51 & 0.48 \\
\hline $\mathrm{y}$ & 1.73 & 1 & 1.26 & 1 & 2.07 & 1 & 1.49 & 1 & 0.99 & 1 & 0.88 & 1 & 0.48 & 0.59 \\
\hline $\mathrm{k}$ & 0.59 & 0.36 & 0.51 & 0.34 & 0.68 & 0.39 & 0.63 & 0.15 & 0.44 & 0.27 & 0.42 & 0.51 & 0.65 & 0.67 \\
\hline $\mathrm{h}$ & 1.88 & 0.87 & 0.66 & 0.71 & 2.11 & 0.87 & 0.89 & 0.65 & 1.46 & 0.90 & 0.56 & 0.89 & 0.69 & 0.63 \\
\hline$y / h$ & 0.94 & 0.11 & 0.92 & 0.86 & 1.06 & 0.23 & 1.13 & 0.80 & 0.72 & -0.46 & 0.46 & 0.84 & 0.68 & 0.41 \\
\hline \hline
\end{tabular}


Let us compare the previous table with table 8. The direction of change for the volatilities of the different variables of interest is not unilateral. For example, while the volatility of consumption is larger in the multivariate setting, the volatility of capital is lower. The performance of the deterministic trend model, however, improves in accounting for the volatility slowdown of investment, capital, and hours.

\section{G.2.2 Stochastic Growth Model}

Let us consider the following

$$
\begin{aligned}
\ln A_{t} & =\ln A_{t-1}+\gamma_{a} t+\varepsilon_{a t} \\
\ln V_{t} & =\ln V_{t-1}+\gamma_{v} t+\varepsilon_{v t}
\end{aligned}
$$

and we assume

$$
\left(\begin{array}{c}
\varepsilon_{a t} \\
\varepsilon_{v t}
\end{array}\right)=\Gamma_{1}\left(\begin{array}{c}
\varepsilon_{a t-1} \\
\varepsilon_{v t-1}
\end{array}\right)+\left(\begin{array}{c}
\xi_{a t} \\
\xi_{v t}
\end{array}\right)
$$

where

$$
\left(\begin{array}{l}
\xi_{a t} \\
\xi_{v t}
\end{array}\right) \sim \mathcal{N}\left(\mathbf{0}, \Sigma_{\xi}\right)
$$

The results from the estimation of the above specification are reported in the following table.

Table 29: Stochastic Trend: Estimated Parameters

\begin{tabular}{|c|c|c|c|}
\hline \hline & $1948: 1-2006: 4$ & $1948: 1-1983: 4$ & $1984: 1-2006: 4$ \\
\hline \hline$\gamma_{a}$ & 0.000619 & 0.001489 & -0.000734 \\
\hline$\gamma_{v}$ & 0.00643 & 0.00493 & 0.008762 \\
\hline$\Gamma$ & $\left(\begin{array}{cc}0.024185 & -0.205103^{*} \\
0.070240^{*} & 0.805801^{*}\end{array}\right)$ & $\left(\begin{array}{cc}0.055551 & -0.178899 \\
0.065821 & 0.782526^{*}\end{array}\right)$ & $\left(\begin{array}{cc}-0.191304 & 0.017916 \\
0.105430^{*} & 0.732534^{*}\end{array}\right)$ \\
\hline$\Sigma_{\xi}$ & $\left(\begin{array}{cc}5.30 \cdot 10^{-5} & -6.96 \cdot 10^{-6} \\
\cdot & 1.14 \cdot 10^{-5}\end{array}\right)$ & $\left(\begin{array}{cc}7.35 \cdot 10^{-5} & -9.31 \cdot 10^{-6} \\
\cdot & 1.54 \cdot 10^{-5}\end{array}\right)$ & $\left(\begin{array}{cc}1.98 \cdot 10^{-5} & -2.561 \cdot 10^{-6} \\
\cdot & 4.91 \cdot 10^{-6}\end{array}\right)$ \\
\hline
\end{tabular}

Our results for this model economy are reported in the following table: 
Table 30: Stochastic Trend: Multivariate Analysis Results

\begin{tabular}{|lcccc|cccc|ccccc|c|}
\hline \hline & \multicolumn{3}{c|}{$1948: 1-2006: 4$} & \multicolumn{4}{c|}{$1948: 1-1983: 4$} & \multicolumn{5}{c|}{$1984: 1-2006: 4$} & \multicolumn{2}{c|}{$\sigma_{\text {post }} / \sigma_{\text {pre }}$} \\
& $\% \sigma_{\text {data }}$ & $\rho_{\text {data }}$ & $\% \sigma_{\text {model }}$ & $\rho_{\text {model }}$ & $\% \sigma_{\text {data }}$ & $\rho_{\text {data }}$ & $\% \sigma_{\text {model }}$ & $\rho_{\text {model }}$ & $\% \sigma_{\text {data }}$ & $\rho_{\text {data }}$ & $\% \sigma_{\text {model }}$ & $\rho_{\text {model }}$ & Data & Model \\
\hline \hline $\mathrm{c}$ & 0.92 & 0.78 & 0.68 & 0.95 & 1.07 & 0.78 & 0.78 & 0.96 & 0.62 & 0.81 & 0.41 & 0.95 & 0.58 & 0.53 \\
\hline $\mathrm{x}$ & 5.77 & 0.89 & 2.17 & 0.91 & 6.85 & 0.89 & 2.47 & 0.91 & 3.47 & 0.92 & 1.34 & 0.90 & 0.51 & 0.54 \\
\hline $\mathrm{y}$ & 1.73 & 1 & 1.05 & 1 & 2.07 & 1 & 1.22 & 1 & 0.99 & 1 & 0.63 & 1 & 0.48 & 0.52 \\
\hline $\mathrm{k}$ & 0.59 & 0.36 & 0.22 & 0.32 & 0.68 & 0.39 & 0.25 & 0.31 & 0.44 & 0.27 & 0.13 & 0.32 & 0.65 & 0.52 \\
\hline $\mathrm{h}$ & 1.88 & 0.87 & 0.23 & 0.89 & 2.11 & 0.87 & 0.26 & 0.90 & 1.46 & 0.90 & 0.14 & 0.88 & 0.69 & 0.54 \\
\hline$y / h$ & 0.94 & 0.11 & 0.86 & 0.99 & 1.06 & 0.23 & 0.99 & 0.99 & 0.72 & -0.46 & 0.51 & 0.99 & 0.68 & 0.52 \\
\hline \hline
\end{tabular}


Comparing the previous table with table 12 we conclude that the multivariate specification implies even lower volatilities for all the variables at hand for all the periods. The performance in terms of replicating the magnitude of the Great Moderation, however, does not change significantly.

From this analysis, we conclude that there is no a significative gain from using a multivariate specification for the innovations. 